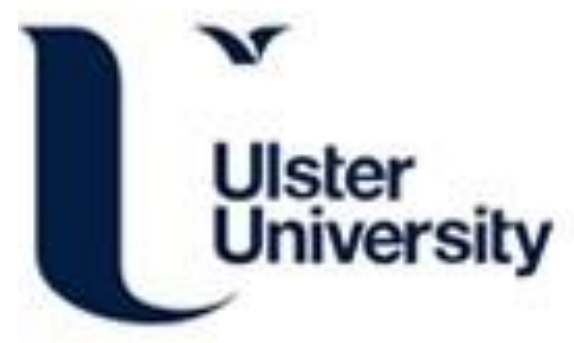

\title{
Numerical validation of pressure peaking from an ignited hydrogen release in a laboratory-scale enclosure and application to a garage scenario
}

Hussein, H., Brennan, S., Shentsov, V., Makarov, DV., \& Molkov, V. (2018). Numerical validation of pressure peaking from an ignited hydrogen release in a laboratory-scale enclosure and application to a garage scenario. International Journal of Hydrogen Energy, 43(37), 17954-17968. https://doi.org/10.1016/j.ijhydene.2018.07.154

Link to publication record in Ulster University Research Portal

\section{Published in:}

International Journal of Hydrogen Energy

Publication Status:

Published (in print/issue): 13/09/2018

DOI:

10.1016/j.ijhydene.2018.07.154

\section{Document Version}

Author Accepted version

\section{General rights}

Copyright for the publications made accessible via Ulster University's Research Portal is retained by the author(s) and / or other copyright owners and it is a condition of accessing these publications that users recognise and abide by the legal requirements associated with these rights.

\section{Take down policy}

The Research Portal is Ulster University's institutional repository that provides access to Ulster's research outputs. Every effort has been made to ensure that content in the Research Portal does not infringe any person's rights, or applicable UK laws. If you discover content in the Research Portal that you believe breaches copyright or violates any law, please contact pure-support@ulster.ac.uk. 


\author{
Elsevier Editorial System(tm) for \\ International Journal of Hydrogen Energy \\ Manuscript Draft
}

Manuscript Number: HE-D-18-01943R1

Title: Numerical validation of pressure peaking from an ignited hydrogen release in a laboratory-scale enclosure and application to a garage scenario

Article Type: Full Length Article

Section/Category: Safety / Sensors

Keywords: Ignited release; hydrogen jet fire; enclosure fire; pressure peaking phenomenon; pressure dynamics; hydrogen safety

Corresponding Author: Dr. Sile Louise Brennan, Ph.D

Corresponding Author's Institution: Ulster University

First Author: Harem G Hussein

Order of Authors: Harem G Hussein; Sile Louise Brennan, Ph.D; Volodymyr Shenstov; Dmitriy Makarov; Vladimir Molkov

Abstract: This work focuses on the overpressures arising from the rapid ignited release of hydrogen in an enclosure, specifically the peak in overpressure that may result in the initial period of the release, dependent on the level of ventilation. Two volumes are considered: a $1 \mathrm{~m} 3$ laboratory scale enclosure for which experimental data exists, and a real scale residential garage. Various vent configurations are considered for each scenario for leak rates typical of those from a fuel cell (laboratory scale enclosure) and from onboard hydrogen storage tanks through a thermally activated pressure relief device (TPRD) in the garage-like enclosure. A validation study has been performed for the laboratory scale enclosure and the modelling approach which gives optimum results has been identified. The influence of heat transfer on the pressure peak has been highlighted, particularly, the importance of radiation in predicting the pressure peak. The validated modelling approach has been applied to a range of experiments and garage scenarios. Both the laboratory and real scale simulations demonstrate the complex relationship between vent size and release rate and indicate the significant overpressures that can result through pressure peaking following an ignited release in an enclosure. The magnitude of the pressure peak as a result of an ignited release has been found to be two orders of magnitude greater than that for the corresponding unignited release. The work indicates that TPRDs currently available for hydrogenpowered vehicles may result in a dangerous situation which should be accounted for in regulations, codes and standards. The application of this work extends beyond TPRDs and is relevant where there is a rapid, ignited release of hydrogen in an enclosure with ventilation. 


\section{Highlights}

- Study on pressure peaking for ignited hydrogen releases in enclosures

- Description and validation of CFD model for ignited pressure peaking phenomena

- Focuses on a small-scale validation case and a real scale residential garage

- Heat transfer, vent size and release rate impact on the pressure peak

- Pressure peak for ignited release 2 orders of magnitude greater than unignited case 


\title{
NUMERICAL VALIDATION OF PRESSURE PEAKING FROM AN IGNITED HYDROGEN RELEASE IN A LABORATORY-SCALE ENCLOSURE AND APPLICATION TO A GARAGE SCENARIO.
}

\author{
Hussein, H. G., Brennan, S.*, Shentsov, V., Makarov D., Molkov, V. \\ HySAFER, School of the Built Environment, Ulster University, BT37 0QB, UK
}

sl.brennan@ulster.ac.uk

Hydrogen Safety Engineering and Research Centre (HySAFER), University of Ulster, Shore Road, Newtownabbey BT37 0QB, UK

\begin{abstract}
This work focuses on the overpressures arising from the rapid ignited release of hydrogen in an enclosure, specifically the peak in overpressure that may result in the initial period of the release, dependent on the level of ventilation. Two volumes are considered: a $1 \mathrm{~m}^{3}$ laboratory scale enclosure for which experimental data exists, and a real scale residential garage. Various vent configurations are considered for each scenario for leak rates typical of those from a fuel cell (laboratory scale enclosure) and from onboard hydrogen storage tanks through a thermally activated pressure relief device (TPRD) in the garage-like enclosure. A validation study has been performed for the laboratory scale enclosure and the modelling approach which gives optimum results has been identified. The influence of heat transfer on the pressure peak has been highlighted, particularly, the importance of radiation in predicting the pressure peak. The validated modelling approach has been applied to a range of experiments and garage scenarios. Both the laboratory and real scale simulations demonstrate the complex relationship between vent size and release rate and indicate the significant overpressures that can result through pressure peaking following an ignited release in an enclosure. The magnitude of the pressure peak as a result of an ignited release has been found to be two orders of magnitude greater than that for the corresponding unignited release. The work indicates that TPRDs currently available for hydrogen-powered vehicles may result in a dangerous situation for the specific scenario considered which should be accounted for in regulations, codes and standards. The application of this work extends beyond TPRDs and is relevant where there is a rapid, ignited release of hydrogen in an enclosure with ventilation.
\end{abstract}

\section{KEYWORDS}

Ignited release, hydrogen jet fire, enclosure fire, pressure peaking phenomenon, pressure dynamics, hydrogen safety, garage enclosure.

\section{INTRODUCTION}

The most common means of hydrogen storage, for both stationary and vehicle applications, is as high pressure compressed gas [1]. Typically, hydrogen storage tanks are fitted with a thermally activated pressure relief device (TPRD) which rapidly releases the hydrogen into the surrounding environment to reduce the potential of tank rupture. By necessity it is practical that hydrogen and fuel cell applications, and hence high-pressure storage tanks are used indoors. Examples of applications include fuel cells in enclosures, vehicles in garages and car parks, hydrogen powered forklifts in warehouses etc. The indoor use of hydrogen and fuel cell applications presents a number of safety issues, several of which have been the focus of recent investigations, including those conducted within the HyIndoor project $[2,13]$.

Previous work by the authors [3] introduced the phenomena of pressure peaking which results from a non-reacting release from hydrogen storage through a TPRD in an enclosure with minimal ventilation. Initially a worst-case scenario was considered of a constant release through a PRD diameter of 5.08 $\mathrm{mm}$ from onboard hydrogen storage at 350 bar in a garage with a single vent of area equivalent to a typical brick. The resultant overpressure has potential to destroy the garage in $3 \mathrm{~s}$. This phenomenon was shown to be pronounced only for hydrogen and to some small extent for methane but not for other combustible gases with a molecular mass higher than air. Subsequent work [4] focused on the overpressure development resulting from a range of hydrogen releases and suggested means by which prohibitive overpressures could be avoided. This pressure peaking phenomenon for the unignited 
release of hydrogen in an enclosure has been well studied analytically [4] and recently validated against experimental data [5]. A detailed explanation of the pressure peaking phenomena for unignited jets, and a simple nomogram can be found in recent work by Brennan et al. [36]. The pressure peaking phenomenon for unignited hydrogen releases was validated against experiment results performed by KIT within the HyIndoor project [6]. The validation experiments were performed in a laboratory scale $1 \mathrm{~m}^{3}$ volume enclosure. A conclusion of the study was that pressure peaking following an unignited release of hydrogen is a hazardous issue which must be considered for the safe indoor use of hydrogen. However, the numerical work on pressure peaking published to date has focused on the consequences of unignited hydrogen releases, resulting from a malfunctioning TPRD. There is a need to investigate the more hazardous scenario of an ignited release from a TPRD in an enclosure, analytical studies have been recently undertaken at Ulster [5]. Indeed, the scenario of an ignited release from a TPRD in an enclosure is more realistic as it is highly probable that the released hydrogen gas immediately ignites [7]. It should be noted that the pressure peaking phenomenon focuses on the pressure which results purely due to the release, and the combustion is non-premixed. A further potentially more hazardous scenario of delayed ignition and subsequent combustion of a premixed cloud is beyond the scope of this work.

Pressure peaking for jet fires was mentioned in a study on the dynamics of hydrogen jet flame selfextinction in an enclosure with single vent [8]. It was demonstrated that overpressure due to jet fires is more hazardous than for unignited release from the same source. A numerical experiment was conducted for a small $1 \mathrm{~m}^{3}$ enclosure with a horizontal vent $(\mathrm{H} \mathrm{x} \mathrm{W}=0.03 \mathrm{~m} \mathrm{x} 0.3 \mathrm{~m})$ and hydrogen leak of $1.085 \mathrm{~g} / \mathrm{s}$ corresponding to a leak flow velocity of $600 \mathrm{~m} / \mathrm{s}$ for the given leak diameter, the overpressure was predicted to be approximately 100 times larger for jet fire scenario compared to the unignited case. However, ignition was not immediate and thus a significant portion of the overpressure was due to delayed ignition and premixed hydrogen-air combustion, a different hydrogen safety issue. Pressure peaking for hydrogen jet fires was not the focus of their study. Previous work at Ulster has considered hydrogen fire regimes in a confined space with passive ventilation for example that by Molkov et al. in 2014. [9].

Free jet fires have been well studied and an overview can be found in the work by Molkov et al [37] limited data exists on jet fires within enclosures. In order to understand the hydrogen jet fire regimes in an enclosure, experiments were performed within the European HyIndoor project (www.hyindoor.eu). It was experimentally found that, in the case of small vent sizes and relatively high hydrogen mass flow rate, under-ventilated hydrogen jet fire led to a significant high overpressure of 1-10 kPa and temperatures of 1000-1200 C [10]. Xiao et al. [11,12] studied the mechanisms of heat transfer in order to numerically simulate hydrogen jet fires in enclosures. They noted overpressure for hydrogen jet fire in a small-scale laboratory enclosure while they experimentally and numerically focused on the effects of heat transfer and heat losses. Computational Fluid Dynamics (CFD) provides a means of gaining insight to the pressure dynamics and flow phenomena following an ignited hydrogen release indoors for a wide range of scenarios. There is a need to have a validated CFD model to predict pressure peaking for ignited hydrogen releases in an enclosure. This study utilises laboratory scale experimental cases recently published [11], to validate a numerical model for hydrogen fires, with a focus on the pressure dynamics. Whilst larger scale experiments of hydrogen fires in enclosures are also presented in the literature [13], these were specifically designed to avoid significant overpressures and were not used in this validation study. The validated model was then applied to a real scale scenario to predict overpressure resulting from an ignited TPRD release in a typical garage cases in order to provide recommendations for a safe vent and TPRD diameter.

\section{PROBLEM DESCRIPTION}

This work focuses on the numerical simulation of the over pressure resulting from an ignited hydrogen release in an enclosure. Two enclosure volumes are considered: a laboratory scale enclosure of approximately $1 \mathrm{~m}^{3}$ and a real scale garage. A numerical validation study has been performed using experimental data from a series of ignited releases in the smaller enclosure, for cases with single and double vents [11]. The validated modelling approach has then been applied to a real scale garage scenario. The validation cases and the garage scenario are described in the following section. 


\subsection{Validation scenario}

A series of experiments were performed at KIT, Germany within the scope of the HyIndoor project, these are summarised here, and full details can be found in the literature [6,11]. Hydrogen releases were considered within a cubic enclosure of approximately $1 \mathrm{~m}^{3}$ (internal dimensions of $1 \mathrm{x} 0.96 \mathrm{x}$ $0.98 \mathrm{~m}$ ). The enclosure consisted of three transparent walls (top, left and right), made from a dual composite of $5 \mathrm{~mm}$ fire protection glass and $15 \mathrm{~mm}$ of Plexiglas, and three $10 \mathrm{~mm}$ thick aluminium walls. A tube nozzle was located in a centre of bottom plate with an internal diameter of $5 \mathrm{~mm}$, which was $0.1 \mathrm{~m}$ above the plate's surface inside the enclosure. Two release rates were considered: 0.5486 $\mathrm{g} / \mathrm{s}$ and $1.086 \mathrm{~g} / \mathrm{s}$ for various vent configurations. All vents were located on front side of the enclosure. Ignition occurred $0.02 \mathrm{~m}$ directly above the tube nozzle and was immediate to avoid delayed ignition. Pressure and temperature dynamics were recorded using a pressure transducer and a grid of 14 thermocouples respectively. A sketch of the enclosure, illustrating the vent configurations is shown in Figure 1.
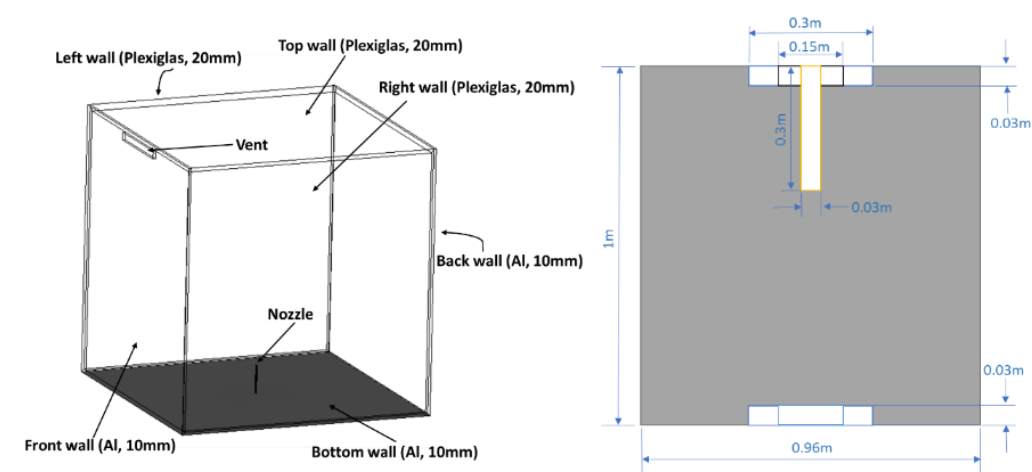

Figure 1. Sketch of the $1 \mathrm{~m}^{3}$ experimental test enclosure (Left) and Front wall of the enclosure (Right) showing all vent openings.

Table 1: Enclosure fire experiments in a laboratory scale enclosure simulated in this study

\begin{tabular}{|c|c|c|c|c|}
\hline $\begin{array}{c}\text { Experiment } \\
\text { number }\end{array}$ & $\begin{array}{l}\text { Vent dimensions } \\
(\mathrm{cm})\end{array}$ & Release rate $(\mathrm{g} / \mathrm{s})$ & $\begin{array}{c}\text { Ambient Pressure } \\
\text { (Pa) }\end{array}$ & $\begin{array}{c}\text { Ambient } \\
\text { Temperature (K) }\end{array}$ \\
\hline \multicolumn{5}{|c|}{$\begin{array}{c}\text { Single Upper Horizontal Vent } \\
\end{array}$} \\
\hline WP4-36 & $3 \times 30$ & 0.5486 & 99669 & 298.5 \\
\hline WP4-58 & $3 \times 30$ & 0.5486 & 100364 & 286 \\
\hline WP4-35 & $3 \times 30$ & 1.086 & 99738 & 301.2 \\
\hline WP4-57 & $3 \times 30$ & 1.086 & 100263 & 286 \\
\hline WP4-14 & $3 \times 15$ & 0.5486 & 101261 & 299.4 \\
\hline WP4-16 & $3 \times 15$ & 1.086 & 100480 & 294.6 \\
\hline \multicolumn{5}{|c|}{ Single Upper Vertical Vent } \\
\hline WP4-20 & $3 \times 30$ & 0.5486 & 99729 & 289.4 \\
\hline WP4-21 & $3 \times 30$ & 1.086 & 99768 & 296.5 \\
\hline \multicolumn{5}{|c|}{ Single Lower Horizontal Vent } \\
\hline WP4-18 & $3 \times 30$ & 0.5486 & 100444 & 302.7 \\
\hline WP4-61 & $3 \times 30$ & 1.086 & 100157 & 300 \\
\hline \multicolumn{5}{|c|}{ Upper and Lower Horizontal Vent } \\
\hline WP4-31 & $2 \times 3 \times 15$ & 0.5486 & 100355 & 305.8 \\
\hline WP4-33 & $2 \times 3 \times 15$ & 1.086 & 99675 & 290.6 \\
\hline WP4-59 & $2 \times 3 \times 15$ & 1.086 & 100268 & 300 \\
\hline
\end{tabular}

Table 1 indicates the 13 experiments simulated in this study, those in bold have been the focus of the validation study but all experiments have been simulated to test the model over a range of vent configurations and release rates. For the majority of cases pressure was recorded at $0.25 \mathrm{~s}$ intervals. However, for the 4 cases in bold, pressure was recorded every $0.05 \mathrm{~s}$. This higher frequency of pressure data acquisition was key to capturing the pressure peak which occurred on average between 0.17 and $0.26 \mathrm{~s}$. In the case of the lower frequency data acquisition the authors believe the exact 
pressure peak may have been missed in some experiments. In contrast, all four experiments indicated in bold, and only some of the remaining experiments captured the experimental pressure peaking. It should also be noted that a level of fluctuation was observed in the recorded pressure data. Thus, to find ambient pressure for each case, mean pressure has been calculated before the start of ignition. The data points showed a level of variance. The standard deviation and sample variance was analysed for each pressure trace prior to ignition (i.e. at "steady state") and the standard deviation varied between 0.017 and 0.03 .

\subsection{Real scale garage}

An ignited release from onboard storage in a garage with a single vent was modelled. The garage had internal dimensions $(\mathrm{L} \times \mathrm{W} \times \mathrm{H})=4.5 \times 2.6 \times 2.6 \mathrm{~m}$. Five scenarios were considered by varying the TPRD diameter and the vent area, these are listed in Table 2 . The notional nozzle approach developed at Ulster $[14,15]$ was used to calculate the equivalent diameter for the leak inlet, thus avoiding the need to resolve the under-expanded region of the jet at the TPRD exit.

Table 2: Garage scenarios considered for numerical study

\begin{tabular}{|c|c|c|c|c|}
\hline & $\begin{array}{c}\text { Vent dimensions }(\mathbf{m}) \\
(\mathbf{H} \times \mathbf{~ W})\end{array}$ & $\begin{array}{c}\text { Release rate } \\
(\mathbf{k g} / \mathbf{s})\end{array}$ & $\begin{array}{c}\text { TPRD } \\
\text { diameter }(\mathbf{m})\end{array}$ & $\begin{array}{c}\text { Notional nozzle } \\
\text { diameter }(\mathbf{m})\end{array}$ \\
\hline Case 1 & $0.35 \times 0.55$ & 0.299 & 0.00334 & 0.0564 \\
\hline Case 2 & $0.95 \times 0.90$ & 0.299 & 0.00334 & 0.0564 \\
\hline Case 3 & $0.65 \times 0.9$ & 0.299 & 0.00334 & 0.0564 \\
\hline Case 4 & $0.35 \times 0.55$ & 0.107 & 0.002 & 0.0338 \\
\hline Case 5 & $0.05 \times 0.25$ & 0.0067 & 0.0005 & 0.00844 \\
\hline
\end{tabular}

Cases $1-3$ investigate the effect off different vent areas. Cases 4 and 5 examine a reduced TPRD diameter. The vent in Case 5 is similar to that investigated in previous work [16], which was considered as a worst garage case scenario, the difference here is the TPRD diameter has been reduced from $5.08 \mathrm{~mm}$ to $0.5 \mathrm{~mm}$ for safety.

\section{MODEL AND NUMERICAL APPROACH}

\subsection{Overview}

As discussed, there are no previous numerical studies on pressure peaking phenomenon for ignited hydrogen releases. CFD can be considered as one of the most advanced tools, which can successfully be used to solve fluid and combustion problems, providing insight to the entire process. Including the prediction of flammable zone formation, temperature gradient, and flow patterns inside the enclosure. A validation study, using the experimental data described in section 2.1, was performed as part of this work before subsequently applying the validated numerical model to real scale cases. A range of models for various aspects of the flow were considered. The model descriptions in the following sections focus on those found to give best results in this study.

For all simulations, ICEM CFD was used to generate the geometries and meshes, with ANSYS Fluent to solve the governing equations. A pressure-based solver has been used. The ideal gas equation was applied to calculate density in the compressible flow. In the laboratory scale experiments the hydrogen velocity was a minimum of $300 \mathrm{~m} / \mathrm{s}$ at the nozzle (Mach number $\geq 0.244$ ), and a notional nozzle approach was used in the garage scale simulations. But most importantly, overpressure dynamics and pressure peaking are the focus of this study and this behaviour can be expected to cause significant changes in density and pressure. PISO (Pressure implicit with the splitting of operators) was applied in this study because it is appropriate for transient flow calculations. Moreover, second order upwind schemes have been used for all spatial discretisation, with the exception of the pressure gradient where the PRESTO! interpolation method was applied. It should be noted that a second order scheme was also considered for pressure interpolation, and results are presented in Section 5.5. However, this was found to overpredict pressure dynamics. A least-squares cell-based approach has been used for interpolation methods (gradients). A first order and bounded second order transient formulation scheme were investigated, and both approaches predicted similar results hence a first order approach was taken to reduce computational expense. 


\subsection{Governing equation:}

The Reynolds-Average Navier-Stokes (RANS) conservation equations were consider solving mass, momentum, energy and species.

$\frac{\partial \rho}{\partial t}+\frac{\partial \rho U_{i}}{\partial x_{i}}=0$

$\frac{\partial\left(\rho U_{i}\right)}{\partial t}+\frac{\partial\left(\rho U_{i} U_{j}\right)}{\partial x_{i}}=-\frac{\partial P}{\partial x_{i}}+\frac{\partial}{\partial x_{j}}\left(\mu+\mu_{t}\right)\left(\frac{\partial U_{i}}{\partial x_{j}}+\frac{\partial U_{j}}{\partial x_{i}}-\frac{2}{3} \frac{\partial U_{k}}{\partial x_{k}} \delta_{i j}\right)+\rho g_{i}$

$\frac{\partial(\rho E)}{\partial t}+\frac{\partial}{\partial x_{i}}\left(U_{i}(\rho E+p)\right)=\frac{\partial}{\partial x_{i}}\left[\begin{array}{c}\left(k+\frac{\mu_{t} c_{p}}{P r_{t}}\right) \frac{\partial T}{\partial x_{i}}-\sum_{m} h_{m}\left(-\left(\rho D_{m}+\frac{\mu_{t}}{S c_{t}}\right)\right)+ \\ U_{i}\left(\mu+\mu_{t}\right)\left(\frac{\partial U_{i}}{\partial x_{j}}+\frac{\partial U_{j}}{\partial x_{i}}-\frac{2}{3} \frac{\partial U_{k}}{\partial x_{k}} \delta_{i j}\right)\end{array}\right]+S_{E}$

$\frac{\partial\left(\rho Y_{m}\right)}{\partial t}+\frac{\partial}{\partial x_{i}}\left(\rho U_{i} Y_{m}\right)=\frac{\partial}{\partial x_{i}}\left[\left(\rho D_{m}+\frac{\mu_{t}}{S c_{t}}\right) \frac{\partial Y_{m}}{\partial x_{i}}\right]+S_{m}$

Where $t$ is time, $\rho$ is density, $i, j$ and $k$ correspond to the Cartesian coordinates, $\mu_{t}$ is turbulent dynamic viscosity, $p$ is pressure, $u$ is the velocity components, $E$ is total energy, $\delta_{i j}$ is the Kronecker symbol, $c_{p}$ is specific heat at constant pressure, $g_{i}$ is gravity acceleration, $S c_{t}$ and $P r_{t}$ are the turbulent Schmidt and energy turbulent Prandtl numbers, which are 0.7 and 0.85 respectively, $Y_{m}$ is the mass fraction, $D_{m}$ is the molecular diffusivity of the species $\mathrm{m}, S_{m}$ and $S_{E}$ are the source terms in the energy equation and $m$ chemical species transport equation.

\subsection{Turbulence model}

The Realizable $k-\varepsilon$ turbulent model [16] was considered to solve the transport equation for turbulence kinetic energy $(\mathrm{k})$ and turbulent dissipation rate $(\varepsilon)$ :

$\frac{\partial(\rho k)}{\partial t}+\frac{\partial}{\partial x_{i}}\left(\rho k U_{i}\right)=\frac{\partial}{\partial x_{i}}\left[\left(\mu+\frac{\mu_{t}}{\sigma_{k}}\right) \frac{\partial k}{\partial x_{i}}\right]+G_{k}+G_{b}-\rho \varepsilon-Y_{m}$
$\frac{\partial(\rho \varepsilon)}{\partial t}+\frac{\partial}{\partial x_{i}}\left(\rho \varepsilon U_{i}\right)=\frac{\partial}{\partial x_{i}}\left[\left(\mu+\frac{\mu_{t}}{\sigma_{\varepsilon}}\right) \frac{\partial \varepsilon}{\partial x_{i}}\right]+\rho C_{1} S \varepsilon-\rho C_{2} \frac{\varepsilon^{2}}{k+\sqrt{v \varepsilon}}-C_{1 \varepsilon} \frac{\varepsilon}{k} C_{3 \varepsilon} G_{b}$

Where, $Y_{m}$ is the contribution of the fluctuating dilatation in compressible turbulence to the overall dissipation rate, $G_{b}$ and $G_{k}$ are buoyancy and mean velocity gradient respectively, which presents the $\mathrm{k}$ generation, $v$ is the kinematic viscosity, $\sigma_{k}$ and $\sigma_{\varepsilon}$ are the Prandtl number of turbulence for $k$ and $\varepsilon$, corresponding to 1 and 1.2. $C_{3 \varepsilon}$ is calculated as a function of the flow velocity components with respect to the gravitational vector while $C_{2}$ and $C_{1 \varepsilon}$ are constants 1.9 and 1.44 respectively. $C_{1}$ is evaluated as function of the modulus of the mean rate of strain sensor, S. Additional turbulent models such as RNG k- $\varepsilon$ model [18], K-omega model SST [19, 20] and Reynolds Stress 7 equations model [21] were also considered for comparison. However, a full model description is not included here.

\subsection{Combustion model}

The Eddy Dissipation Concept (EDC) model has been used. EDC is an extension of the eddy dissipation model with an extensive chemical reaction mechanism for turbulent flow [22]. In this study, 18 chemical reactions with 9 species are considered for hydrogen-air mixture combustion. A complete description of the chemical reaction mechanism can be found in previous work [9]. The reaction rate of species $i$ by EDC model can be evaluated as:

$$
R_{i}=\frac{\rho\left(\xi^{*}\right)^{2}}{\tau^{*}\left[1-\left(\xi^{*}\right)^{3}\right]}\left(Y_{i}^{*}-Y_{i}\right)
$$

When time scale, $\tau^{*}$, and the fine scale length, $\xi^{*}$, can be calculated as follows [23]:

$\tau^{*}=C_{\tau}\left(\frac{v}{\varepsilon}\right)^{1 / 2}$ 
$\xi^{*}=C_{\xi}\left(\frac{v \varepsilon}{k^{2}}\right)^{1 / 4}$

Where $C_{r}$ and $C_{\xi}$ are the time scale and volume fraction constant, which are equal to 0.4082 and 2.137 respectively, $R_{i}$ is a net rate of production/destruction of species $i$ by chemical reactions, $Y_{i}$ is a species $i$ mass fraction in the surrounding fine-scales state, $Y_{i}^{*}$ is the fine scale mass fraction of species $i$ after reacting over the time $\tau^{*}$ [24] The Laminar Finite Rate (LFR) model was also considered for comparison but is not described in detail here. It should be noted that condensation of the water vapour formed by the combustion process was not considered for either geometry. The relative humidity in the enclosure was monitored in each case and was much lower than 50\% in initial period of the release where the pressure peaking occurred. Moreover, Xiao et al. [11] considered condensation in their study for hydrogen jet fires in an enclosure with the same geometry as considered for validation here, and predicted that the first seconds of the simulation, where the pressure peaking might occur, were not influenced by condensation.

\subsection{Radiation:}

The Discrete Ordinates (DO) model was used to account for radiation [25]. For a finite number of solid angles $\Omega^{\prime}$ associated to the direction $\vec{s}$ the Radiative Transfer Equations (RTE) is calculated:

$\nabla(I(\vec{r}, \vec{s}) \vec{s})+\left(\kappa+\sigma_{s}\right) I(\vec{r}, \vec{s})=\kappa n^{2} \frac{\sigma T^{4}}{\pi}+\frac{\sigma_{s}}{4 \pi} \int_{0}^{4 \pi} I\left(\vec{r}, \vec{s}^{\prime}\right) \phi\left(\vec{s} . \vec{s}^{\prime}\right) d \Omega^{\prime}$

Where $\sigma_{s}$ indicates the scattering coefficient, $\kappa$ is the absorption coefficient, $n$ is the refractive index, $\vec{r}$ is the position vector in $\vec{s}$ direction and $\phi$ is the scattering phase function.

Since the product of hydrogen combustion is water vapour, the Exponential wide band (EWB) model, suggested by Yan et al. [26] is used in this study. The model has been tested and validated against experimental results in previous work at Ulster [27]. The radiative transfer equation (RTE) was discretised by using $3 \times 3$ pixels and $5 \times 5$ angular divisions. The number of control angles associated to the RTE can be determined by the number of Theta and Phi divisions. It is recommended that $5 \times 5$ divisions are a strong candidate to be used for the variation of temperature in space [28]. However, a previous study [27] investigated the effect of radiation model angular discretisation, and $12 \times 12,10 \mathrm{x}$ $10,7 \times 7$ and $5 \times 5$ angular discretisation were compared. For their geometry and simulation, $10 \times 10$ or above provided better results on the sensors to receive the radiation emitted by the flame along all its length. Nevertheless, the computational time for their small geometry increased by 1.9 times and the differences are comparably minor. In addition, initial simulations in this study showed that the differences between $5 \times 5$ and $10 \times 10$ are negligible for the large scales considered here and are computationally highly expensive. Therefore, 5 x 5 angular divisions have been accounted for in this study.

\section{LABORATORY SCALE ENCLOSURE SIMULATION DETAILS 4.1 Computational domain}

A domain with outer dimensions $3 \times 2 \times 4 \mathrm{~m}(\mathrm{H} \mathrm{x} \mathrm{W} \mathrm{x} \mathrm{L)} \mathrm{was} \mathrm{used.} \mathrm{The} \mathrm{cubic} \mathrm{enclosure} \mathrm{with} \mathrm{internal}$ dimensions of $1 \times 0.96 \times 0.98 \mathrm{~m}(\mathrm{H} \times \mathrm{W} \times \mathrm{D})$ was positioned such that the domain boundaries were $0.5 \mathrm{~m}$ from the enclosure walls except for the front and top, which were $2.5 \mathrm{~m}$ and $2 \mathrm{~m}$ from the boundary respectively. The non-symmetrical positioning of the enclosure within the domain, and the domain size was chosen to ensure the outer boundaries did not affect the flow field. The enclosure walls represented both Plexiglas and aluminium panels with a thickness of $0.02 \mathrm{~m}$ and $0.01 \mathrm{~m}$ respectively. A hexahedral mesh was used throughout, including in the enclosure walls, and three mesh configurations were considered as part of a mesh independency study. A box mesh technique was used around the tube nozzle, at the leak to ensure a more refined mesh for this high gradient zone and provide a smoother grid transition. The nozzle inlet was modeled as a single square cell with an edge length of $0.0044 \mathrm{~m}$.

\subsection{Material properties}


Three materials were used in this study: aluminium and Plexiglas in the validation cases and aluminium and concrete in the garage scenarios. Material properties used are illustrated in the Table 3.

Table 3: Material properties used in simulations

\begin{tabular}{|c|c|c|c|}
\hline & Aluminium & Plexiglas & Concrete \\
\hline Density $\left(\mathrm{kg} / \mathrm{m}^{3}\right)$ & 2719 & 1180 & 2400 \\
\hline Specific heat $\left(\mathrm{c}_{\mathrm{p}}\right)(\mathrm{j} / \mathrm{kg}-\mathrm{k})$ & 871 & 1465 & 900 \\
\hline Thermal conductivity $(\mathrm{w} / \mathrm{m}-\mathrm{k})$ & 202.4 & 0.19 & 1.5 \\
\hline Absorption coefficient $(1 / \mathrm{m})$ & 0 & 0.3 & 0 \\
\hline Internal Emissivity & 0.09 & 0.86 & 0.85 \\
\hline
\end{tabular}

\subsection{Boundary and Initial Conditions}

Mass flow rate, and total temperature were specified at the leak inlet. A user defined function (UDF) was used to increase the mass flow rate of hydrogen linearly from zero at a flow time of zero to a constant leak rate at $0.01 \mathrm{~s}$, mimicking valve opening. The corresponding total temperature was calculated using isentropic flow relationships. Turbulence kinetic energy $(\mathrm{k})$ and dissipation rate $(\varepsilon)$ at the leak inlet were accounted for explicitly. A pressure outlet condition was applied for the domain boundaries. A coupled wall boundary was used for the two-sided walls, whereby one side is fluid and the other side is a solid. This was essential to capture conduction heat transfer, which may play an important role in hydrogen jet fire simulations [11]. All walls of the enclosure were two-sided. A noslip condition was applied at the solid surfaces. Initial conditions for pressure and temperature were based on experimental data.

\subsection{Simulation ignition}

Temperature patching was used to ignite hydrogen and the "hot spot" was maintained until reasonable $\mathrm{OH}$ species was detected in the simulation (approx. $0.01 \%$ vol. $\mathrm{OH}$ ) this is generally accepted value associated with flame at normal conditions [23]. The region where temperature was patched was explicitly specified, ensuring the ignition properly occurred. In the validation simulations the "hot spot" was at a position $0.02 \mathrm{~m}$ above the leak nozzle. For the real garage case a region $0.2 \mathrm{~m}$ higher the inlet was used.

\section{LABORATORY SCALE ENCLOSURE RESULTS}

\subsection{Time Step Independence Study}

Time step is an important criterion which controls the accuracy and stability of numerical simulations. The choice of the time step for fully-implicit scheme, such as the one used here, may affect the accuracy of transient phenomena predictions and the solver convergence [29,30]. An extensive timestep sensitivity study (or equivalent Courant-Friedrichs-Lewy number (CFL)/Courant number) was conducted to understand the sensitivity of simulation results. Emphasis was placed on ensuring a time step independent solution as initial work indicated that pressure peak prediction for an ignited hydrogen release is highly dependent on time step. To comply with CFD model evaluation protocol [30], a reasonable CFL was initially chosen and then reduced by half until a time-step independent solution was achieved. Given that CFL number is a function of both the smallest cell size and the flow velocity, even with a leak inlet modelled as a single cell, a time-step of the order of 7.3333E-06 s was required to ensure a CFL of 0.5 for a mass flow rate of $0.5486 \mathrm{~g} / \mathrm{s}$. Such a time step led to prohibitive computational times. Therefore, understanding to what extent the CFL number can be increased was considered as a necessity in this case to avoid months of calculation on a high-performance computer.

A time step independence study was performed for the case of a release rate of $0.5486 \mathrm{~g} / \mathrm{s}$ into an enclosure with a single upper horizontal vent $(3 \mathrm{~cm} \times 30 \mathrm{~cm})$ i.e. experiment WP4-58 in Table 1 . Constant CFL numbers of $1,7.5$ and 15 were considered, in addition to a scenario whereby the CFL number was gradually increased from 0.5 to 7.5 over a flow time of $0.1 \mathrm{~s}$. The numerical results are compared with experimental data in Figure 2. A constant CFL of 1 gives good agreement with 
experimental results in the prediction of the overpressure peak. A constant CFL of 7.5 leads to an underprediction of pressure by a minor difference of $3.4 \%$ compared to a CFL of 1 . However, by increasing the CFL the computational time is 7.5 times faster than a CFL of 1 , meaning that simulation results can be achieved within a week on a high performance computer with 64 cores . Using a CFL of 15 the pressure peak was overpredicted by approx $10.7 \%$ and the timing of the peak was delayed. A gradually increasing CFL provided good agreement with experimental data and results were comparable to those with a constant CFL of 1 . Thus, gradually increasing the CFL allows for a reduction in overall computational time, whilst achieving the same level of accuracy as a constant CFL of 1. An increase in CFL results in a delay in pressure peaking, this may be explained by considering the later ignition of the hydrogen. When there is high gradient such in e.g. temperature or velocity, a lower CFL number is required to initiate ignition at the correct time. For higher CFL numbers the delay in ignition means that when ignition is initiated more hydrogen is available to burn, leading to a higher-pressure peak, and a higher maximum mole fraction of combustion products such as hydroxyl $(\mathrm{OH})$, which later decrease and stabilise, this is illustrated in Figure 3.

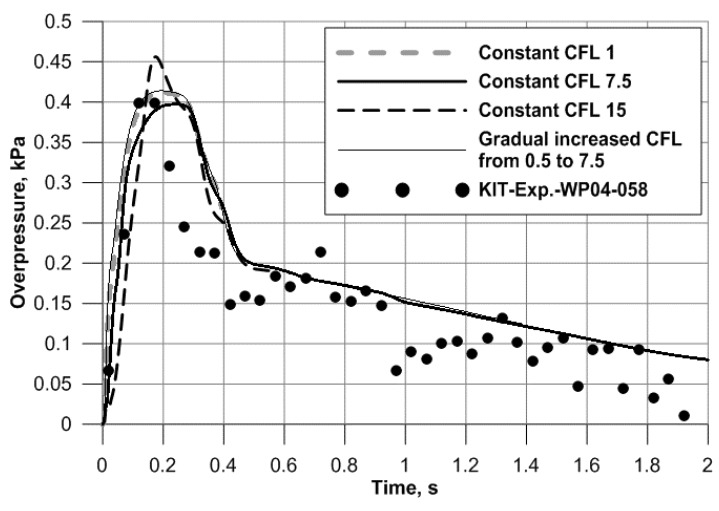

Figure 2: Overpressure versus time for a range of CFL values, for a release rate of $0.5486 \mathrm{~g} / \mathrm{s}$ in a $1 \mathrm{~m}^{3}$ enclosure with a horizontal vent of $3 \mathrm{~cm}$ by $30 \mathrm{~cm}$. (WP04-058)

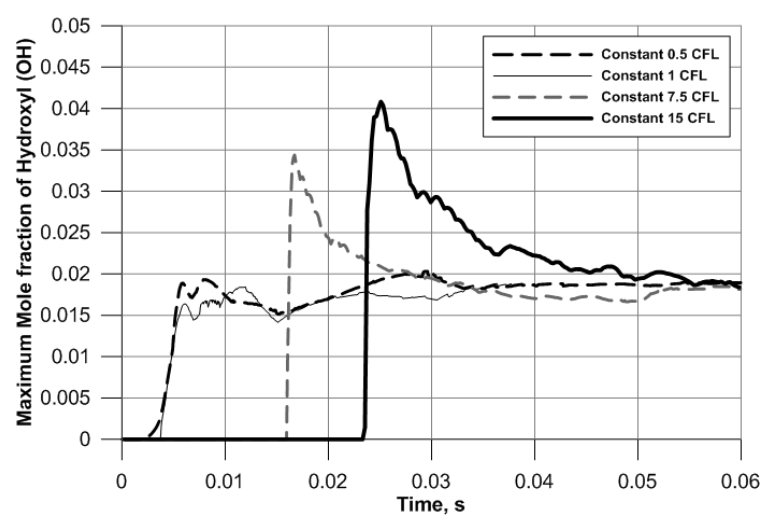

Figure 3: Maximum Hydroxyl $(\mathrm{OH})$ concentration versus time, for a range of CFL values, for a release rate of $0.5486 \mathrm{~g} / \mathrm{s}$ in a $1 \mathrm{~m}^{3}$ enclosure with a horizontal vent of $3 \mathrm{~cm}$ by $30 \mathrm{~cm}$. (WP04-058)

A similar analysis was carried out for two further cases from Table 1: (WP4-36) is almost identical to that shown in Figure 2 with slightly different ambient conditions and (WP4-35) where the release rate is doubled to $1.086 \mathrm{~g} / \mathrm{s}$. This analysis gave results which further supported the use of a CFL of 7.5 to provide acceptable results in a shorter time for this study.

\subsection{Grid Independence}

In order to comply with the CFD model evaluation protocol [30], three different grids were simulated (coarse, intermediate, and refined). In each grid refinement, the average length of the computational cells was halved in all regions, particularly in areas where high gradients and complex phenomena were expected. Special refinement was provided around the hydrogen inlet and the enclosure volume for all grids as recommended in [29]. The mesh details are summarised in Table 4 and overpressure results for a release rate of $0.5486 \mathrm{~g} / \mathrm{s}$ in a $1 \mathrm{~m}^{3}$ enclosure with a horizontal vent of $3 \mathrm{~cm}$ by $30 \mathrm{~cm}$. (WP04-058) are presented in Figure 4. All simulations were run on 64 cores of a HPC. It should be noted, that whilst not presented here, a study was performed to examine the effect of the number of cells at the leak point. This showed that in this particular occasion, the number of cells at the inlet had no effect on the hydrogen mass flow rate exit at the nozzle, and the subsequent combustion and overpressure peak. Modelling the inlet this way greatly improved simulation run time, as the inlet cell is the smallest cell in the calculation domain, and the point with the highest velocity, thus the maximum CFL is at this position. Detailed understanding of the dispersion of hydrogen around the nozzle was not the focus of the work presented here.

Table 4: Mesh details for grid independence study

\begin{tabular}{|c|c|c|c|c|c|}
\hline Mesh size & No. Cells & No. Faces & No. Nodes & Cells at leak & $\begin{array}{c}\text { Computational time to } \\
\text { 0.5 s flow time }\end{array}$ \\
\hline
\end{tabular}




\begin{tabular}{|cl|c|c|c|c|c|}
\hline 1. & Coarse & 59,788 & 215,084 & 72,825 & one & 2 days \\
\hline 2. & Intermediate & 486,2675 & $1,608,871$ & 541,058 & one & 7 days \\
\hline 3. & Refine & $3,112,358$ & $9,890,673$ & $3,308,245$ & four & 73 days \\
\hline
\end{tabular}

Only minor differences in overpressure are observed between the coarse and intermediate meshes, although some fluctuation in the results were observed for the coarser mesh. Both the coarse and intermediate meshes predicted overpressure 5\% lower than those predicted by the refined mesh. However, both the coarse and intermediate meshes were within $1.25 \%$ and $0.5 \%$ of the maximum experimental overpressure. A constant CFL of 7.5 was used for all three cases. It has been estimated that if a CFL of 1 were to be used for the refined mesh, the computational time for $0.5 \mathrm{~s}$ of flow time would be in the region of 547 days on a 64-core machine! This is not a viable approach hence techniques such as localised mesh refinement, the use of one cell at the inlet and optimisation of time step and grid were employed. The results of the grid independence study demonstrate that the mesh sizes considered have a minor effect on predicting the pressure peak. However, the coarse mesh was not considered further, due to fluctuations detected in the predicted pressure dynamics, and a concern that such a grid might not fully capture the entire flow process. However, if one is only interested in the maximum pressure peak value, a coarse mesh might be used to provide a preliminary result in a short time. A refined mesh may provide accurate results but required excessive computational time. Therefore, the intermediate mesh was used for the validation study as it provides good agreement with experimental results, and a comparably high level of accuracy, whilst using less computational resources.

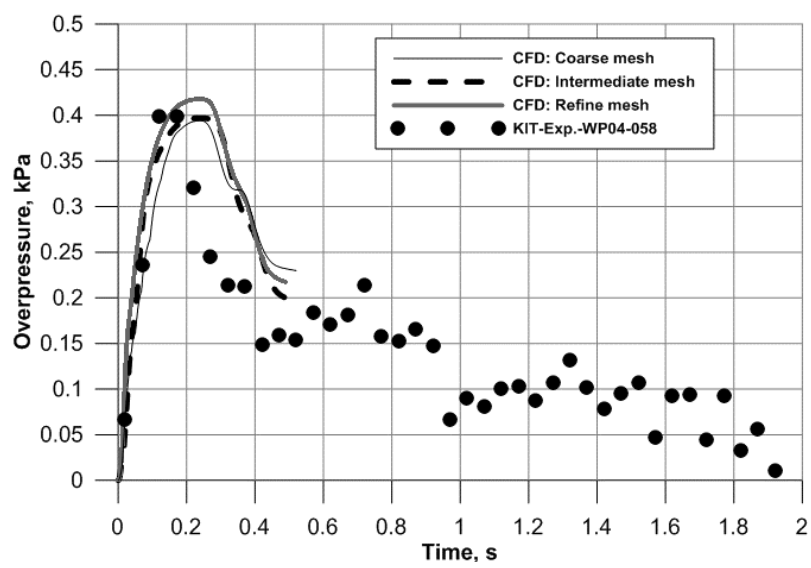

Figure 4: Overpressure versus time for three mesh resolutions, for a release rate of $0.5486 \mathrm{~g} / \mathrm{s}$ in a $1 \mathrm{~m}^{3}$ enclosure with a horizontal vent of $3 \mathrm{~cm}$ by $30 \mathrm{~cm}$. (WP04-058) (Constant CFL 7.5)

\subsection{The influence of ambient temperature and pressure on enclosure overpressure}

More than one test was performed for a number of the experimental configurations, i.e. the same the same geometric configuration and leak rate are considered but the ambient pressure and temperature conditions differ (Table 1). In order to understand the sensitivity of overpressure dynamics and the maximum pressure peak to ambient conditions, two experimental configurations have been simulated. Both experiments WP04-36 and WP04-58 involve a release rate of $0.5486 \mathrm{~g} / \mathrm{s}$ in a $1 \mathrm{~m}^{3}$ enclosure with a horizontal vent of $3 \mathrm{~cm}$ by $30 \mathrm{~cm}$ (Table 1). However, there is a difference in the two experiments of $694.35 \mathrm{~Pa}$ and $12.53 \mathrm{~K}$ in ambient pressure and temperature respectively. Both sets of experimental data (WP04-36 and WP04-58) and the corresponding numerical simulations are presented in Figure 5. It should be noted, that in the simulations presented CFL was gradually increased from 0.5 to 7.5 as discussed in Section 5.1. The frequency of data acquisition was lower in the case of WP04-36 and it is clear the pressure peak was missed in the experimental data. No other significant difference is observed between the experiments, and the variation in most points is lower than $5 \%$. 


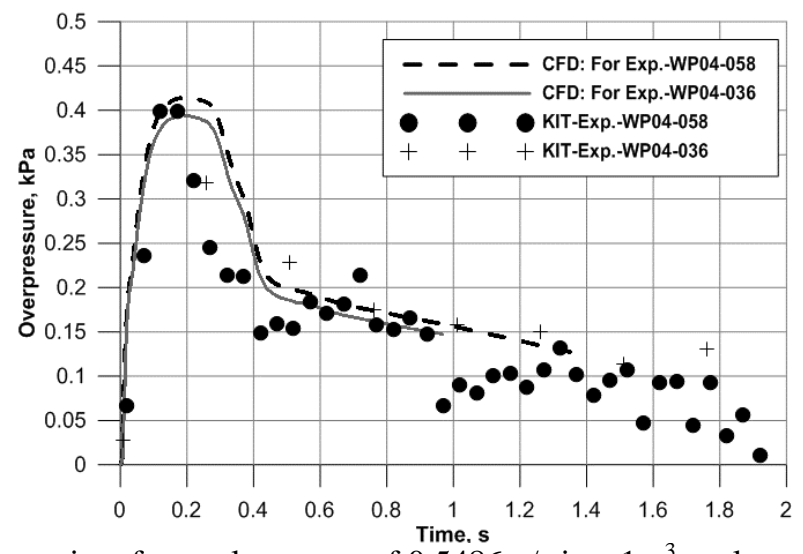

Figure 5: Overpressure versus time for a release rate of $0.5486 \mathrm{~g} / \mathrm{s}$ in a $1 \mathrm{~m}^{3}$ enclosure with a horizontal vent of $3 \mathrm{~cm}$ by $30 \mathrm{~cm}$ for differing ambient conditions.

The simulations for both ambient conditions predicted similar pressure peaking, and the difference between the simulation predictions is less than $5 \%$. The experimental and numerical results show that there will be no significant different in overpressure prediction if the simulation or experiment are carried out under varying ambient conditions. However, the results in Figure 5 shed light on the fact that those experiments where pressure was recorded at $0.25 \mathrm{~s}$ time intervals may not have successfully captured the pressure peak. A similar analysis was performed for experiments WP04-035 and WP0457 and the results confirm that there is negligible difference between overpressure value for the different ambient conditions. Hence, experimental cases with higher frequency data acquisition where the main focus of this validation, with the remaining cases included for comparison.

\subsection{The effect of turbulence model on pressure dynamics}

The effect of four different turbulence models was examined for a release rate of $0.5486 \mathrm{~g} / \mathrm{s}$ in a $1 \mathrm{~m}^{3}$ enclosure with a horizontal vent of $3 \mathrm{~cm}$ by $30 \mathrm{~cm}$. The ambient conditions in WP04-036 (99669.35Pa and $298.53 \mathrm{~K}$ ) were used in simulations, however experimental data from experiment WP04-058 (100363.7Pa and 286K) is also considered for comparison following the analysis in Section 5.3 previously. Results for overpressure in the enclosure are shown in Figure 6. The K-omega SST model led to divergence and unphysical flame defragmentation. This turbulent model is recommended for flows close to the wall although the focus in this study is to reproduce pressure peaking and hydrogen jet fire, mostly at a distance from the wall boundary. The RSM turbulence model (7 equation) overpredicted the pressure peak by $8.6 \%$, and the peak was delayed by approximately $1 \mathrm{~s}$. Similar behaviour can be seen for RNG k-epsilon model, but the peak value has been successfully captured. The Realizable k-epsilon model provided good agreement with the experimental data points. Previous studies in hydrogen jet fires have indicated good results for RNG k-epsilon [9,31]. However, the most recent study supports the use of Realizable k-epsilon for better experimental agreement [26]. RNG and Realizable k-epsilon models were also compared for a release rate of $1.086 \mathrm{~g} / \mathrm{s}$ in a $1 \mathrm{~m}^{3}$ enclosure with a horizontal vent of $3 \mathrm{~cm}$ by $30 \mathrm{~cm}$, whilst these are not presented here the Realizable $\mathrm{k}$-epsilon model provided better prediction of the pressure peak. 


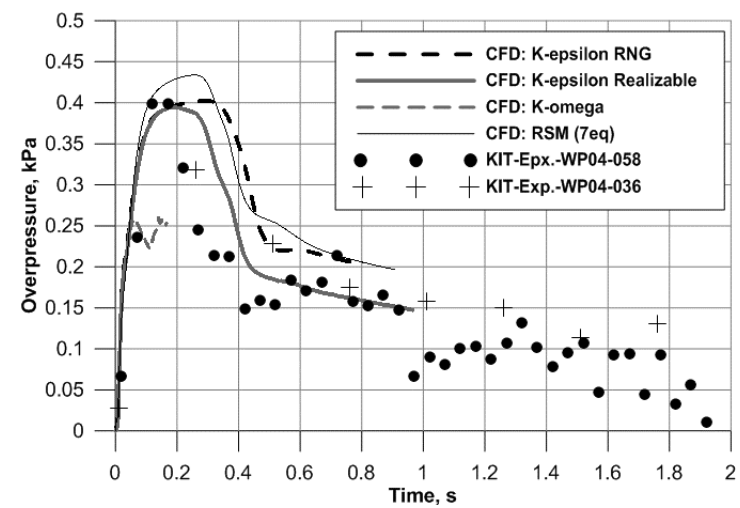

Figure 6: Effect of turbulence model on overpressure for a release rate of $0.5486 \mathrm{~g} / \mathrm{s}$ in a $1 \mathrm{~m}^{3}$ enclosure with a horizontal vent of $3 \mathrm{~cm}$ by $30 \mathrm{~cm}$. (WP04-036)

\subsection{The effect of pressure interpolation scheme}

Both second order and PRESTO! (Pressure Staggering Option) schemes were compared to understand their effect on overpressure inside the enclosure. From Figure 7 it can be seen that the overpressure predicted using the PRESTO! scheme more closely matched the experimental results.

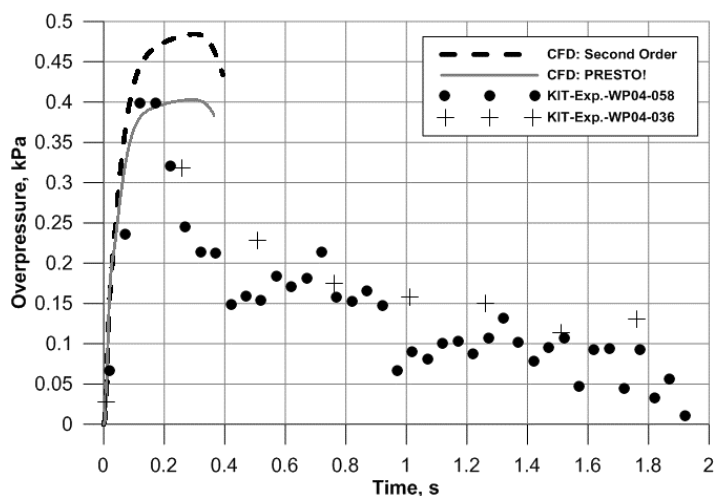

Figure 7: The effect of second order and PRESTO! interpolation schemes on overpressure for a release rate of $0.5486 \mathrm{~g} / \mathrm{s}$ in a $1 \mathrm{~m}^{3}$ enclosure with a horizontal vent of $3 \mathrm{~cm}$ by $30 \mathrm{~cm}$. (WP04-036)

\subsection{The effect of combustion model on enclosure overpressure}

The Eddy Dissipation Concept model (EDC) has been compared to the Laminar finite rate model (LFR) and the results are presented in Figure 8. It can be clearly seen how EDC can be used to better predict overpressure inside the enclosure whilst LFR overpredicts the result by appoximately $20 \%$.

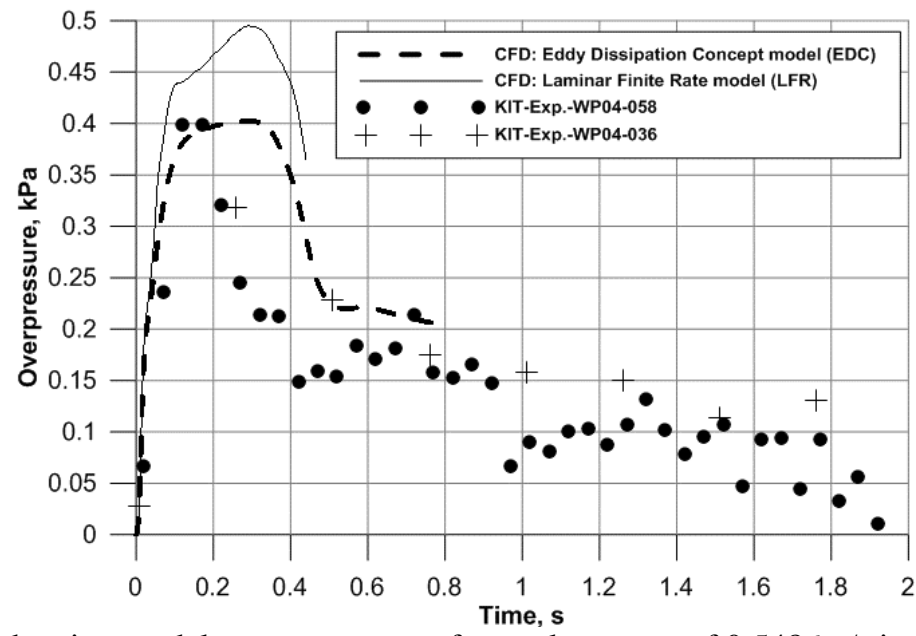

Figure 8: Effect of combustion model on overpressure for a release rate of $0.5486 \mathrm{~g} / \mathrm{s}$ in a $1 \mathrm{~m}^{3}$ enclosure with a horizontal vent of $3 \mathrm{~cm}$ by $30 \mathrm{~cm}$. (WP04-036) 
5.6 The influence of heat transfer on enclosure pressure dynamics

Four simulations have been performed to investigate the effect of heat transfer mechanisms on pressure peaking for a release rate of $0.5486 \mathrm{~g} / \mathrm{s}$ in a $1 \mathrm{~m}^{3}$ enclosure with a horizontal vent of $3 \mathrm{~cm}$ by $30 \mathrm{~cm}$. (WP04-058). The results are presented in Figure 9.

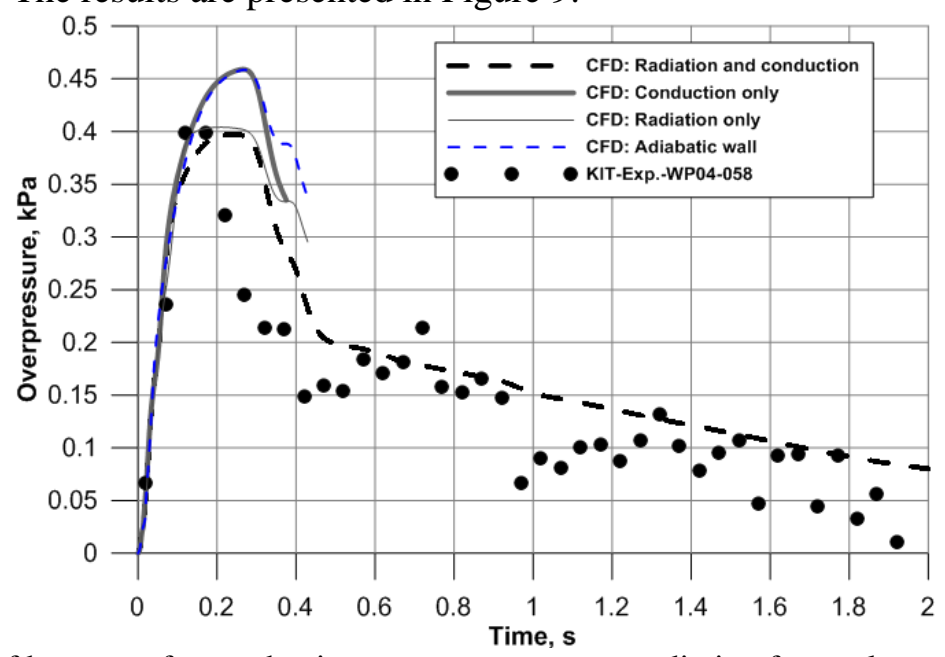

Figure 9: The effect of heat transfer mechanisms on overpressure prediction for a release rate of $0.5486 \mathrm{~g} / \mathrm{s}$ in a $1 \mathrm{~m}^{3}$ enclosure with a horizontal vent of $3 \mathrm{~cm}$ by $30 \mathrm{~cm}$. (WP04-058)

All heat transfer mechanisms were considered within one simulation (CFD: Radiation and Conduction). A simulation with adiabatic walls, did not account for heat transfer through the enclosure walls or via radiation, and led to an overprediction of $12.8 \%$ compared to the experimental results. When conduction heat transfer through the enclosure walls was considered (CFD: Conduction only), the overprediction marginally improved $(0.1 \%)$ although the effect of conduction increased after the peak. Since the pressure peak for this small laboratory scale enclosure occurs in a fraction of a second, there is insufficient time for conduction to be effective. The importance of radiative heat transfer, whilst computationally intensive, for pressure peak prediction is clearly demonstrated.

\subsection{Absorption coefficient and the effect of humidity}

The absorption coefficient (Y) described by Yan et al. [26] has been compared with Hubbard and Tien's Plank mean absorption coefficient (HT) [32] to evaluate their overpressure prediction. The main difference between these coefficients appears for temperatures lower than $800 \mathrm{~K}$, where the $\mathrm{Y}$ coefficient is lower than the HT coefficient. In order to understand the real effects of these two absorption coefficients, two simulations were performed and compared to experimental results, again for the case of a release of $0.5486 \mathrm{~g} / \mathrm{s}$ in a $1 \mathrm{~m}^{3}$ enclosure with a horizontal vent of $3 \mathrm{~cm}$ by $30 \mathrm{~cm}$ (WP04-058). The results are presented in Figure 10, where it can be seen that both absorption coefficients have predicted almost identical pressure dynamics. This can be explained by the fact that the temperature due to hydrogen combustion is roughly the same and heats the room at a similar rate. Since the adiabatic flame temperature is $2354 \mathrm{~K}$ and the focus of this study is on hydrogen jet fires in an enclosure, there will not be a significant difference in results between using either of these absorption coefficients. However, it should be noted here that the air was initially assumed completely dry. The effect of relative humidity is discussed below.

The relative humidity in the air was not measured at the time of the experiments, and accounting for humidity using archive metrological data might not provide accurate details. The data shows in [33] that the outside ambient temperature at the time of KIT experiment (WP04-58) was 18 C. Relative humidity at this temperature may be around $40 \%$. With this in mind, a value of $50 \%$ has been investigated, for comparison with dry air, to understand the effect of humidity in the air on pressure peaking prediction. Cirrone et al. [27] studied the effect of air humidity on radiative heat flux for hydrogen jet fires, and it was shown that relative humidity might have an impact on reproducing experimental data. Two simulations were conducted, and the effect of wet air (50\% RH) has been compared to dry air for both Yan et al. (2015) [26] and Hubbard and Tien (1978) [32] absorption coefficients as can be seen in figure 10. Whilst there is minimal difference between these two 
absorption coefficients in terms of pressure peaking prediction for dry air, there is $8.8 \%$ difference between these two models for overpressure prediction when humidity is accounted for.

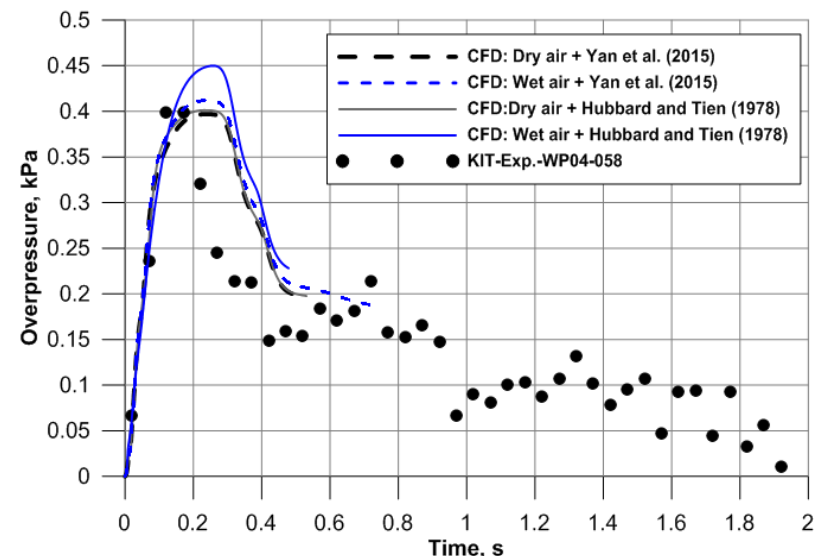

Figure 10: Effect of relative humidity on pressure dynamics for a release rate of $0.5486 \mathrm{~g} / \mathrm{s}$ in a $1 \mathrm{~m}^{3}$ enclosure with a horizontal vent of $3 \mathrm{~cm}$ by $30 \mathrm{~cm}$. (WP04-058)

The Hubbard and Tien (1978) absorption coefficient with wet air overpredicts overpressure by about $11 \%$ compared to KIT experimental result for (WP04-58) and the same coefficient with dry air simulation. In contrast, the Yan et al. (2015) coefficient with wet air has overpredicted the result only by around $2 \%$ against both experimental and dry air simulation results. Therefore, the Yan et al. (2015) absorption coefficient has been chosen in this study to predict pressure peaking for hydrogen jet fires. Since there is no data available for relative humidity or mass fraction of water vapour in air, dry air was considered for all simulations presented in this paper. The effect of humidity was included here for completeness of analysis, however, as demonstrated it was found to have a negligible effect on the results for this particular study hence the authors are confident in the assumption of dry air for the results presented in the following sections.

\subsection{Results of numerical validation}

In order to provide the best validation study possible, those experiments with higher frequency data acquisition (Table 1) were the main focus of the validation study. However, all experiments in Table 1 were simulated and presented here and in Section 5.9 For validation purposes a release rate of 0.5486 $\mathrm{g} / \mathrm{s}$ with a single horizontal vent was considered, in addition to a higher a release rate of $1.086 \mathrm{~g} / \mathrm{s}$ for three vent configurations.

The scenario of a release rate of $0.5486 \mathrm{~g} / \mathrm{s}$ in a $1 \mathrm{~m}^{3}$ enclosure with a horizontal vent of $3 \mathrm{~cm}$ by 30 $\mathrm{cm}$. (WP04-058) was chosen as the first validation case for numerical model selection due to the resolution of pressure data but also because the lower release rate of $0.5486 \mathrm{~g} / \mathrm{s}$, led to quicker simulations. As shown in figure 11, there is good agreement between the KIT experimental data and CFD simulation, and the pressure peak has been successfully reproduced. There is a minor overprediction in the numerical simulation by $2 \%$. A number of factors may have contributed to this difference. For example, the recorded experiment mass flow rate was less than $0.5486 \mathrm{~g} / \mathrm{s}$ by 0.0038 $\mathrm{g} / \mathrm{s}$ in the initial stages of the release and there are some fluctuations in the pressure data points as discussed previously. However, overall, pressure decay over time has also been well predicted. Hence the validated modelling approach was applied to a wider range of experiments and real scale scenarios. In the simulation presented in Figure 11, CFL was increased gradually from 0.5 initially to 7.5 (See discussion in section 5.1).

The numerical results predicted that the overpressure inside the enclosure is homogenous, and no spatial variation was found in the initial pressure peaking phase. CFD does however, provide an insight into the dynamics of flame development as illustrated in Figure 12. 

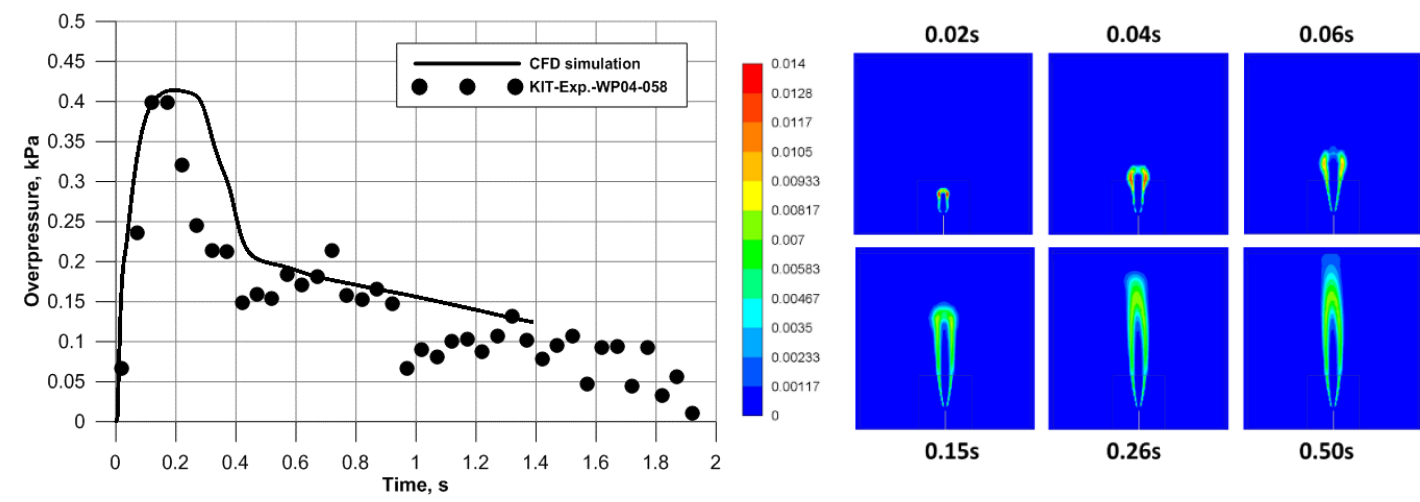

$0.08 \mathrm{~s}$
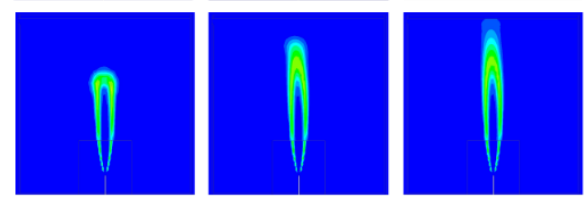

$0.26 s$

$0.50 \mathrm{~s}$

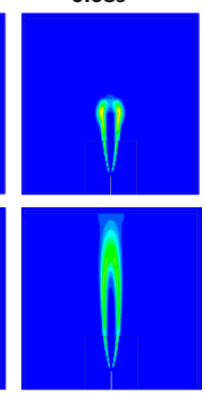

$2.96 s$

Figure 11: Overpressure versus time, a comparison between CFD and experimental results for a release rate of $0.5486 \mathrm{~g} / \mathrm{s}$ in a $1 \mathrm{~m}^{3}$ enclosure with a horizontal vent of $3 \mathrm{~cm}$ by 30 cm. (WP04-058)
Figure 12: Contours of hydroxyl mole fraction showing flame development in the centre plane of the $1 \mathrm{~m}^{3}$ enclosure for a release rate of $0.5486 \mathrm{~g} / \mathrm{s}$ and a horizontal vent $3 \mathrm{~cm}$ by $30 \mathrm{~cm}$. (WP04-058)

Three experiments (Table 1) involving a higher mass flow of $1.086 \mathrm{~g} / \mathrm{s}$ into an enclosure were also considered for validation, each had the same total vent area but different vent positions: 1 . single upper horizontal vent $3 \mathrm{~cm}$ by $30 \mathrm{~cm}$ (WP04-57), 2. single lower horizontal vent $3 \mathrm{~cm}$ by $30 \mathrm{~cm}$ (WP04-61) and 3. upper and lower vent with dimensions $3 \mathrm{~cm}$ by $15 \mathrm{~cm}$. The results for the three vent configurations can be seen in Figure 13.

In the case of the upper vent, the simulation overpredicted the pressure peak by $25 \%$, which is the highest level of overprediction in this study and it was recorded in this case. There are many factors that may have contributed to this overprediction. For example, the standard deviation in pressure measurements for this experiment was around $\pm 0.029 \mathrm{kPa}$, which makes the result vary by almost $5 \%$. It can be noted how two of the experimental pressure points for the upper vent case, following ignition show similar values, this differs from all other cases where the pressure rises immediately following ignition. Fluctuation is also observed in the experimental mass flow rate, with the actual mas flow rate at the time of the peak $0.003 \mathrm{~kg} / \mathrm{s}$ less than that in the simulation. However, there is good agreement in the timing of the maximum overpressure and the overall trend shows good agreement with the experimental results. The numerical overpressure prediction for this case is 3.5 times higher than the same vent configuration but lower mass flow rate (WP04-58). This indicates that for increasing mass flow rate the maximum over pressure increases nonlinearly showing the significant effect of mass flow rate on pressure peaking for an ignited hydrogen release inside an enclosure.

Considering the lower vent case shown there is a good agreement between simulation and experimental results. With an underprediction of approximately $13 \%$ near the peak. This is considered an acceptable engineering error by the authors given the potential uncertainty and factors discussed previously. The duration of the pressure peak for the $1.086 \mathrm{~g} / \mathrm{s}$ release is twice the duration of that presented for the $0.5486 \mathrm{~g} / \mathrm{s}$ release. The reduction in overpressure is not immediate, and it decreases linearly at a slower rate in the case of the lower vent compared with the upper vent. The lower vent does not allow the hot gas in the top layer of the enclosure to escape as easily as when an upper vent is present. The presence of accumulated hot products can be seen in by analysing the CFD results, verifying this. A small difference $(0.1 \mathrm{kPa})$ is observed between the maximum over pressure predicted by the lower vent simulation but it is not clear if this may be attributed to variation in ambient conditions. The final validation configuration was that with two vents, one higher and one lower, each with dimensions $3 \mathrm{~cm}$ by $15 \mathrm{~cm}$ (WP04-59), and hence the same overall vent area as the cases discussed above. Good agreement was achieved between the simulation and experimental results, with an overprediction of approximately $11 \%$. The duration of the pressure peak is lower than that for 
the lower vent case and the rate of reduction in overpressure was longer than in the upper vent case but half that of the lower vent scenario.

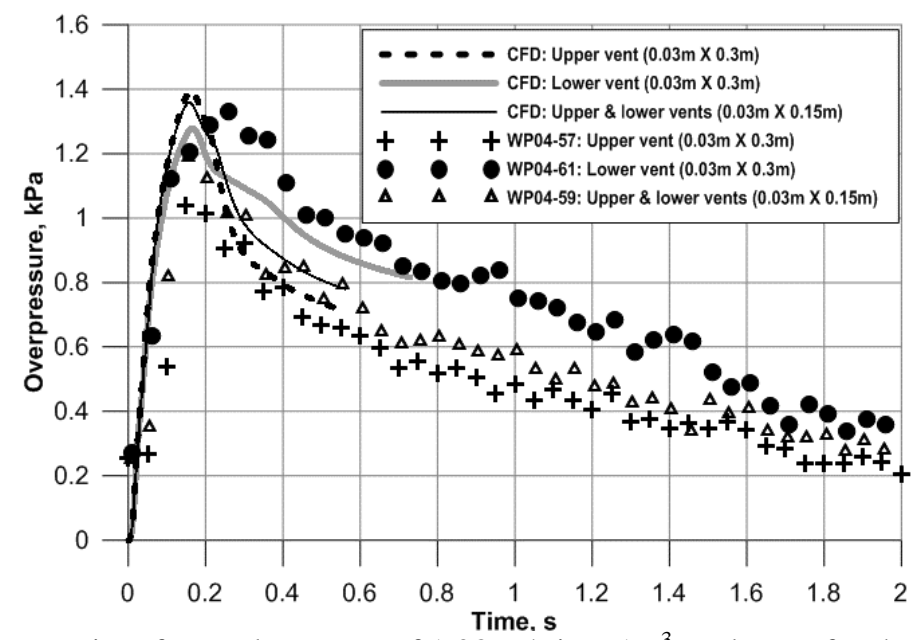

Figure 13: Overpressure vs time for a release rate of $1.086 \mathrm{~g} / \mathrm{s}$ in a $1 \mathrm{~m}^{3}$ enclosure for three vent configurations: upper vent of $3 \mathrm{~cm}$ by $30 \mathrm{~cm}$, lower vent of $3 \mathrm{~cm}$ by $30 \mathrm{~cm}$ and higher and lower vents of $3 \mathrm{~cm}$ by $15 \mathrm{~cm}$.

It can be concluded that the numerical approach can be used successfully to predict pressure peaking phenomenon for ignited hydrogen release inside the enclosure. However, an extensive study is recommended to address the effect of vent location on the magnitude and duration of pressure peaking for an ignited release. In a real scale enclosure, such as a garage, the duration of the pressure peak cannot be neglected due to potential impact on the durability of the building structure.

\subsection{Application of validated model to range of laboratory scale experiments}

The validated modelling approach was applied to eight further experiments. It should be noted that in the experiments described in this section, pressure data was recorded at intervals of $0.25 \mathrm{~s}$. Given the pressure peak occurs in many cases before this time, it can be assumed that the peak was missed in the experiments where it occurred before $0.25 \mathrm{~s}$. The simulations included four simulations for a release rate of $0.5484 \mathrm{~g} / \mathrm{s}$ and four for a release rate of $1.084 \mathrm{~g} / \mathrm{s}$. The reader is referred to Table 1 for ambient conditions in each case as they vary across the experiments. The vent configurations considered are 1. A single horizontal upper vent $(3 \mathrm{~cm}$ x $30 \mathrm{~cm}), 2$. A single vertical upper vent $(3 \mathrm{~cm} \times 30 \mathrm{~cm}), 3$. A small single upper horizontal vent $(3 \mathrm{~cm} \times 15 \mathrm{~cm})$, and 4 . A combination of an upper and lower vent $(3 \mathrm{~cm} \times 15 \mathrm{~cm})$. The results for a release of $0.5484 \mathrm{~g} / \mathrm{s}$ can be seen in Figure 14, and those for a release of $1.084 \mathrm{~g} / \mathrm{s}$ are presented in Figure 15. In all cases the CFL was gradually increased from 0.5 to 7.5 .

The two simulations for a horizontal upper vent were similar to those performed for model validation and discussed in the previous sections, the only difference being ambient conditions, good agreement was found between simulation and experiment showing the ability of the model to reproduce experiments in various conditions. There were no experiments with an upper vertical vent which recorded data at intervals smaller than $0.25 \mathrm{~s}$ hence the peak was missed in each case (WP04-20) and (WP04-21), nevertheless there is good agreement between simulations and experimental data. It is noted that the pressure appears to plateau in the experimental results during the time that the numerical analysis predicts a peak, a similar peak was predicted using an analytical approach by Makarov et al. [5], where they note that the experiments with an over pressure higher than $1.5 \mathrm{kPa}$ appear to have exhibited "breathing", i.e. leaking through the joints which may yield lower overpressure in experimental results for these tests. However, this has not been confirmed.

It should be noted that the numerical simulations predicted pressure peaking to be similar for the case of a vertical and horizontal vent for the same release rate. This indicates that the vent configuration does not affect pressure peaking phenomenon for hydrogen jet fires. Whilst vertical vents are known 
to provide better ventilation efficiency in some cases [34], this is based on having both inflow and outflow, whereas here all flow is out through the vent, with no inflow, regardless of vent orientation.

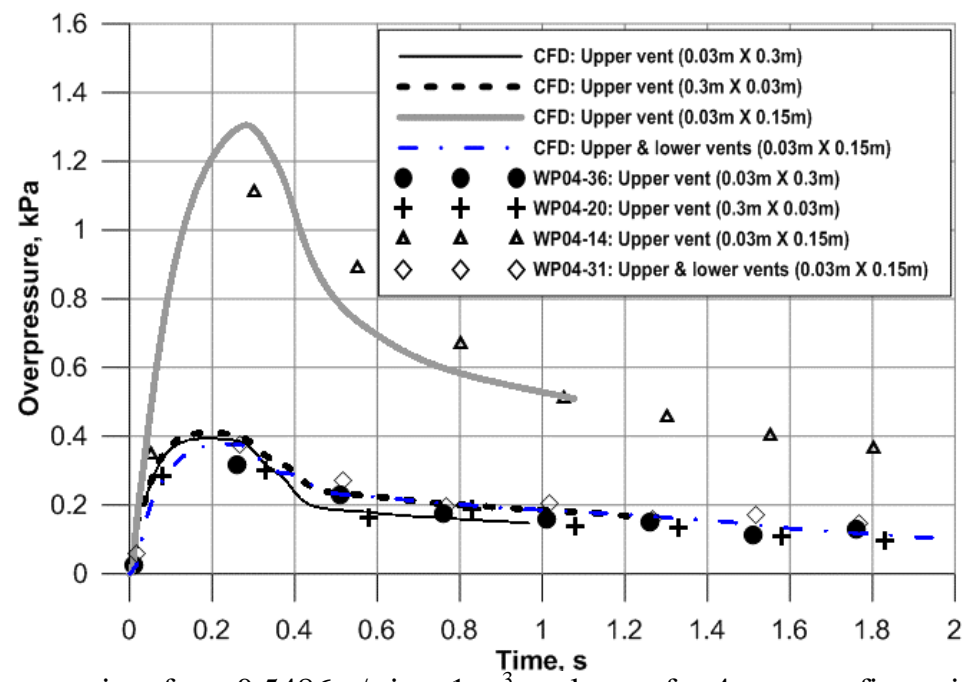

Figure 14: Overpressure vs time for a $0.5486 \mathrm{~g} / \mathrm{s}$ in a $1 \mathrm{~m}^{3}$ enclosure for 4 vent configurations: upper vent $(3 \mathrm{~cm}$ x $30 \mathrm{~cm})$, upper vent $(30 \mathrm{~cm} \times 3 \mathrm{~cm})$, smaller upper vent $(3 \mathrm{~cm} \times 15 \mathrm{~cm})$, and higher and lower vents $(3 \mathrm{~cm} \times 15$ $\mathrm{cm})$.

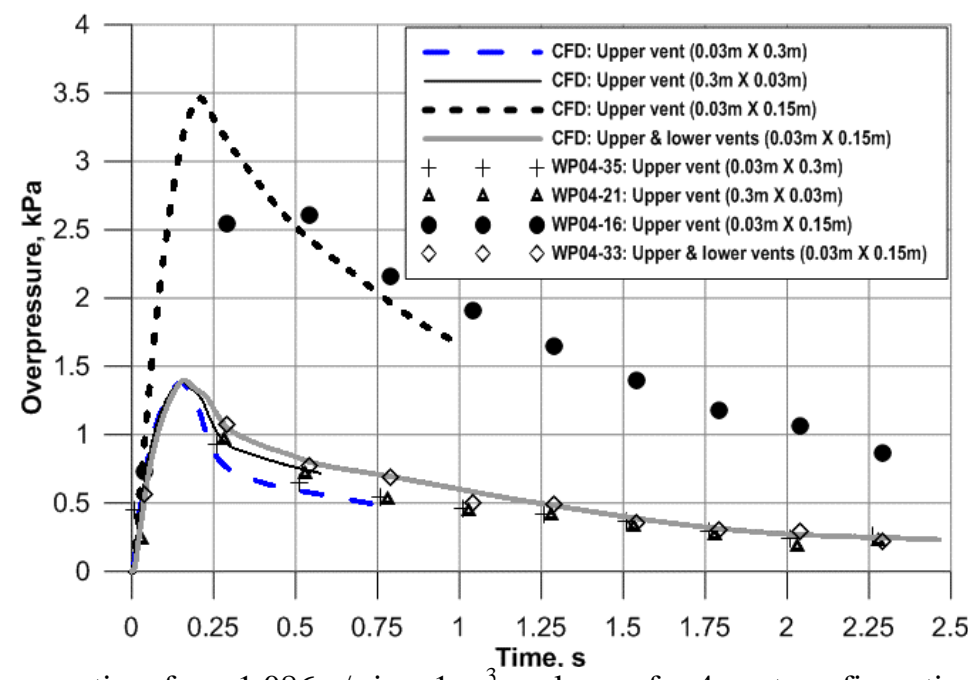

Figure 15: Overpressure vs time for a $1.086 \mathrm{~g} / \mathrm{s}$ in a $1 \mathrm{~m}^{3}$ enclosure for 4 vent configurations: upper vent $(3 \mathrm{~cm} \mathrm{x}$ $30 \mathrm{~cm})$, upper vent $(30 \mathrm{~cm} \times 3 \mathrm{~cm})$, smaller upper vent $(3 \mathrm{~cm} \times 15 \mathrm{~cm})$, and higher and lower vents $(3 \mathrm{~cm} \times 15$

$\mathrm{cm})$.

A smaller horizontal vent of $3 \mathrm{~cm}$ by $15 \mathrm{~cm}$ was simulated for a $0.5486 \mathrm{~g} / \mathrm{s}$ and $1.086 \mathrm{~g} / \mathrm{s}$ release (WP04-14) and (WP04-16). Both simulations showed good agreement with the experimental data. For each case the pressure peak was more than double that for the larger vent area. The cases with smaller upper and lower vents showed good agreement with the experimental results for both release rates and the trends observed are in line with those discussed in Section 5.8 for the validation study. As expected the vent area has a significant effect on pressure peaking phenomenon for hydrogen jet fires and it could be considered as one of the first parameters to change to avoid prohibitive overpressures. It should also be noted that the area of the vent is more important than vent configuration for pressure peaking.

\section{IGNITED RELEASE IN A TYPICAL GARAGE 6.1 Computational details}


The validated modelling approach discussed in Sections 4 and 5 was applied to simulate an ignited release from onboard storage in a typical residential garage. A domain with outer dimensions of $(\mathrm{L} \mathrm{x}$ $\mathrm{W} \times \mathrm{H}=25.67 \times 6.9 \times 11 \mathrm{~m})$ was created, with a garage of dimensions $(\mathrm{L} \times \mathrm{W} \times \mathrm{H}=4.5 \times 2.6 \times 2.6$ $\mathrm{m})$ positioned $18 \mathrm{~m}$ from the outer domain boundary. It was assumed that the garage walls, roof and floor were constructed of concrete with a thickness of $0.15 \mathrm{~m}$. The front wall was considered as the garage door, made of aluminium with a thickness of $0.02 \mathrm{~m}$. The dimensions and material properties are typical of those used in residential UK garages. The five garage cases simulated are listed in Table 2. In all cases, flow is super critical at the TPRD exit and hence the notional nozzle approach by Ulster [15] was used to calculate the equivalent diameter for the leak, thus avoiding the need to resolve the under-expanded region of the jet at the TPRD exit. This approach [15] was used to calculate the mass flow rate, hydrogen temperature and velocity at the notional nozzle. As in the laboratory scale simulations it was assumed that the mass flow rate increases linearly, reaching a steady value after $0.01 \mathrm{~s}$. After this time, it was considered as constant to avoid the complication of blow down, the simulations focus on the very early stage of the release from the $70 \mathrm{MPa}$ tank. The garage cases were considered to be initially $100 \%$ air at STP. Temperature patching was used to ignite hydrogen and the "hot spot" was maintained until reasonable $\mathrm{OH}$ species was detected in the simulation (approx. $0.01 \%$ vol. OH). Temperature was patched in a region $0.2 \mathrm{~m}$ above the leak inlet. A hexahedral mesh was used, with a similar approach to the laboratory scale simulations, the number of control volumes was an average of 540,000 with a greater number $(681,704)$ in case 5 due to the smaller release diameter. A schematic of the garage is given in Figure 16.

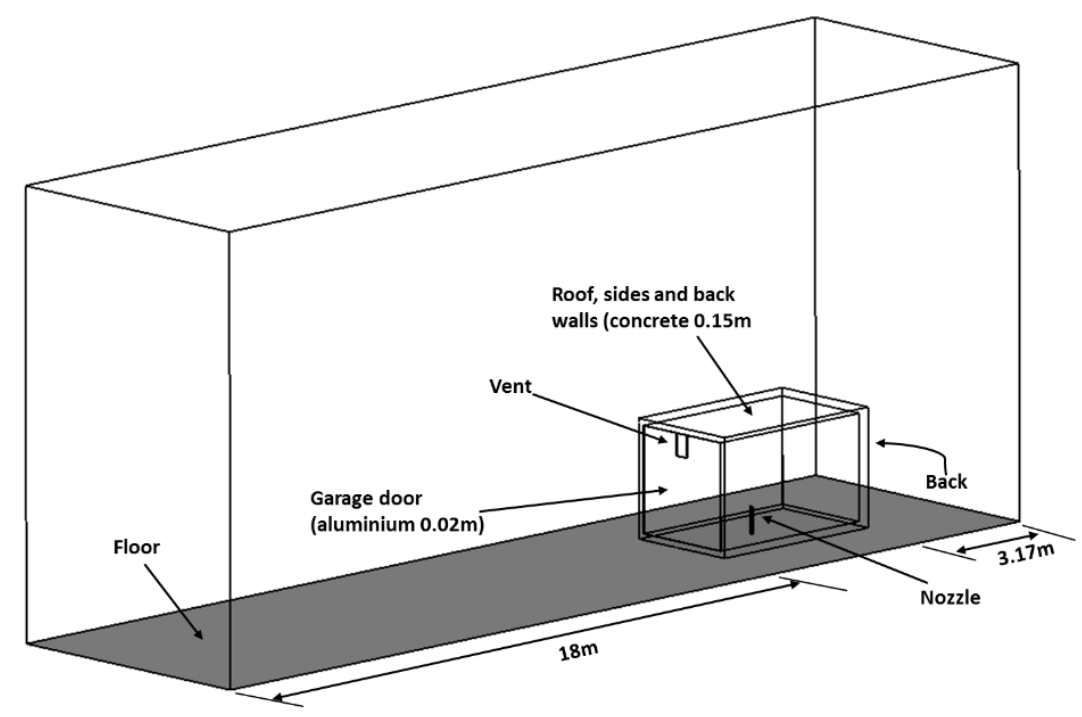

Figure 16. Schematic of garage configuration

\subsection{Results of garage simulations}

In recent work [16] by the authors, a preliminary study was carried out to examine the difference in pressure peaking for an unignited and ignited release. Simulations predicted that the ignited hydrogen release might lead to overpressures two orders of magnitude greater than those reached if the release was unignited. The case considered in [15] was a $0.299 \mathrm{~kg} / \mathrm{s}$ constant release and a $0.55 \mathrm{~m} \mathrm{x} 0.35 \mathrm{~m}$ vent, hence this configuration was the starting point for the work presented here (case 1). Some changes have been made to the simulation approach presented in [16], to reflect the findings of the validation study presented here. Namely, PRESTO! has been used for pressure gradient, realizable $k-\varepsilon$ for turbulence and three-dimensional heat transfer has been modelled at the walls. A time step dependency study was performed for case 1, using the validated modelling approach and the CFL selected was then applied to further cases. Simulations were run with constant CFL numbers of 1, 2.5, 5 and 7.5, the level of precision decreased with increasing CFL. However, the simulation with a CFL of 7.5 was 7.5 times quicker, taking 4-5 days on a 64 core HPC, and the difference in terms of pressure peaking prediction was less than $4 \%$ (Figure 17). As discussed in Section 5.1, the delay in pressure rise with increasing CFL may be explained by the ignition timing. Thus, a CFL of 7.5 was deemed to be sufficient for the garage cases to achieve preliminary results. A CFL of 1 is 
recommended if precise results are required. It can be seen from Figure 17 how a $0.299 \mathrm{~kg} / \mathrm{s}$ constant release and a $0.55 \times 0.35 \mathrm{~m}$ vent results in a predicted overpressure of $42 \mathrm{kPa}$, this is 76 times higher than the overpressure for an unignited hydrogen release in the same configuration. This is significantly higher than the overpressure a garage may typically withstand (10-20 kPa)[35]. These results highlight a clear problem with a TPRD nozzle diameter of $3.34 \mathrm{~mm}$. The vent size of $0.35 \mathrm{x}$ $0.55 \mathrm{~m}$ would be considered "safe" in the event of an unignited release but is far from adequate for the ignited scenario. These results indicate that pressure peaking for hydrogen jet fires is a safety concern which should be considered when hydrogen vehicles are used in a confined space such as a garage. It is important to emphasise, as previously mentioned, that this work is focused on the pressure peaking phenomenon due to immediate ignition of the leak and subsequent non-premixed combustion. A scenario of delayed ignition and subsequent combustion of a premixed cloud is beyond the scope of this work.

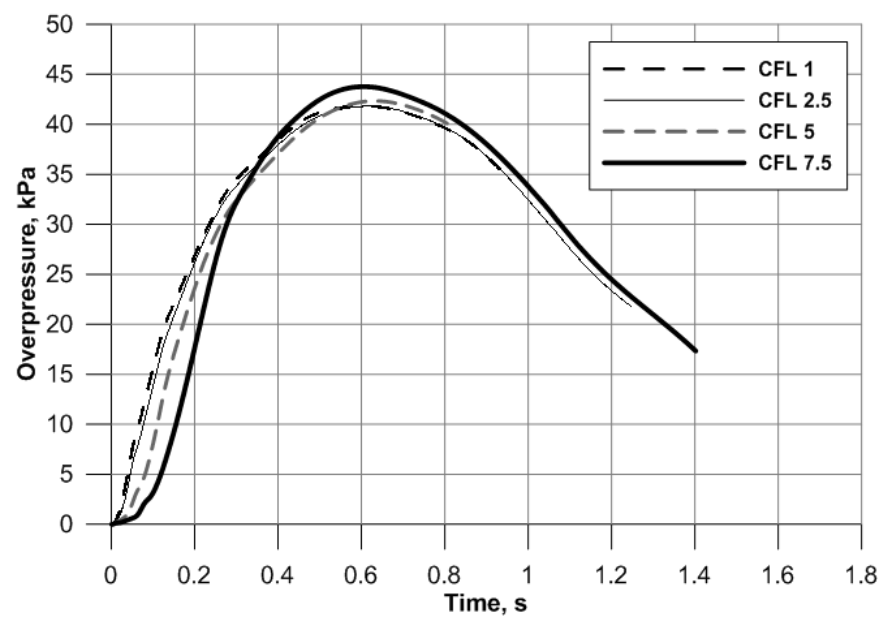

Figure 17 Time step independence study for the garage case. Overpressure versus time for a $3.34 \mathrm{~mm}$ TPRD, $0.299 \mathrm{~kg} / \mathrm{s}$ constant release and a $0.55 \mathrm{~m}$ x $0.35 \mathrm{~m}$ vent.

The overpressure levels reached with case 1 are clearly prohibitive. Thus 4 further scenarios were investigated in order to understand "safe" vent sizes and TPRD diameters: the same TPRD diameter of $3.34 \mathrm{~mm}$ was considered but with larger vent sizes of $0.95 \times 0.90 \mathrm{~m}$ (case 2) and $0.65 \times 0.9 \mathrm{~m}$ (case 3 ), and smaller TPRD diameters of $2 \mathrm{~mm}$ with a vent of $0.35 \times 0.55 \mathrm{~m}$ (case 4), and a TPRD diameter of $0.5 \mathrm{~mm}$ and a vent size of $0.05 \times 0.25 \mathrm{~m}$ (case 5). Results for the 5 cases are shown in Figure 18.

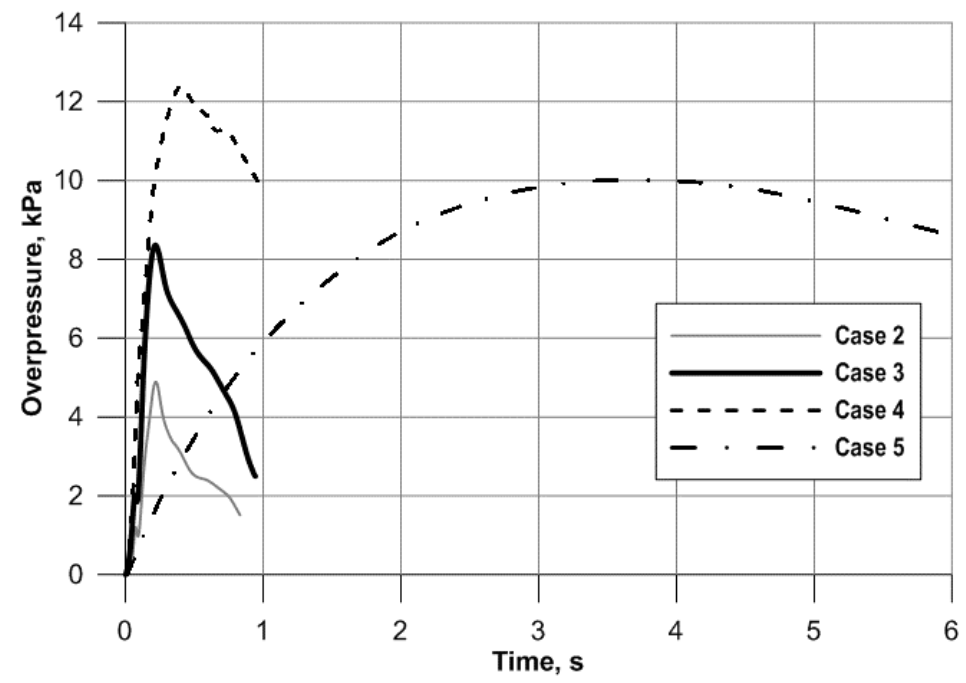

Figure 18. Overpressure versus time for the garage scenarios. Case 2: $3.34 \mathrm{~mm}$ TPRD, $0.95 \mathrm{~m} \times 0.90 \mathrm{~m}$ vent, Case 3: $3.34 \mathrm{~mm}$ TPRD, $0.65 \mathrm{~m}$ x $0.9 \mathrm{~m}$, Case 4: $2 \mathrm{~mm}$ TPRD, $0.35 \mathrm{~m}$ x $0.55 \mathrm{~m}$ vent, Case 5: $0.5 \mathrm{~mm}$ TPRD, $0.05 \mathrm{~m} \times 0.25 \mathrm{~m}$ vent. 
It can be seen from Figure 18 how an increase in vent size to $0.95 \mathrm{~m} \mathrm{x} 0.9 \mathrm{~m}$ for a TPRD diameter of $3.34 \mathrm{~mm}$ leads to a reduction in overpressure to, $4.9 \mathrm{kPa}$, i.e. 8.6 times lower than the $42 \mathrm{kPa}$ predicted for a $0.299 \mathrm{~kg} / \mathrm{s}$ constant release and a $0.55 \times 0.35 \mathrm{~m}$ (case 1), for a corresponding increase in vent size of 4.4, this is less than half the value of pressure likely to cause structural collapse, and hence could be considered a "safe" scenario. However, a vent size of $0.95 \times 0.9 \mathrm{~m}$ is quite large for a residential garage. An intermediate vent size of $0.65 \times 0.9 \mathrm{~m}$ was considered in case 3, resulting in a predicted overpressure of $8.4 \mathrm{kPa}$. Cases 1 to 3 demonstrate that the relationship between vent size and overpressure inside the garage is nonlinear, and has with the laboratory scale experiments, these indicate the significant effect of vent size on pressure peaking for ignited releases. It can be seen from cases 4 and 5 how a reduction in TPRD diameter lead to a reduction in both overpressure and duration of the pressure peak. Rather than rely upon the public to ensure adequate ventilation in residential garages it is recommended that the TPRD diameter for onboard storage be reduced. However, it is acknowledged that the TPRD diameter cannot be considered in isolation, a reduction in leak diameter will increase the time for the storage tank to empty. Thus, the fire resistance of the tanks should also be considered to avoid the scenario of tank rupture.

\section{CONCLUSIONS}

A numerical study of pressure peaking for ignited hydrogen releases in an enclosure has been performed. Two geometries were considered, a small scale $1 \mathrm{~m}^{3}$ enclosure, for which experimental data exists and a real scale residential garage. Studies on the small-scale enclosure formed the basis of a validation study and good agreement was found between overpressure dynamics predicted numerically and the experimental data. The importance of heat transfer mechanisms in the prediction of ignited pressure peaking has been identified, particularly radiation. The sensitivity of simulation results to timestep was highlighted. The validated modelling approach model was applied to simulate pressure peaking following a release through a typical TPRD from onboard storage in a residential garage, this work identified a safety problem with existing TPRD diameters. Both the laboratory and real scale simulations demonstrate the complex relationship between vent size and release rate and indicate the significant overpressures that can result through pressure peaking following an ignited release in an enclosure. However, TPRDs currently available for hydrogen-powered vehicles may result in a highly dangerous situation unless their diameter is reduced below fractions of $\mathrm{mm}$, however it is noted that this cannot be considered independently of the fire resistance rating of the tank. This should be accounted for in regulations, codes and standards. The application of this work extends beyond TPRDs and is relevant where there is a rapid, ignited release of hydrogen in an enclosure with limited ventilation

\section{ACKNOWLEDGEMENTS}

The authors wish to thank Dr Mike Kuznetsov and the team at Karlsruhe Institute of Technology for the guidance on the experimental results used for validation of the numerical studies in this paper.

\section{REFERENCES}

[1] Gangloff RP, Somerday BP. Gaseous Hydrogen Embrittlement of Materials in Energy Technologies: The Problem, its Characterisation and Effects on Particular Alloy Classes. 2012. doi:10.1533/9780857093899.

[2] Fuster B, Houssin-Agbomson D, Jallais S, Vyazmina E, Dang-Nhu G, Bernard-Michel G, et al. Guidelines and recommendations for indoor use of fuel cells and hydrogen systems. Int $\mathrm{J}$ Hydrogen Energy 2017;42:7600-7. doi:10.1016/j.ijhydene.2016.05.266.

[3] Brennan S, Makarov D, Molkov V. Dynamics of Flammable Hydrogen-Air Mixture Formation in an Enclosure with a Single Vent. Sixth Int Semin Fire Explos Hazards 2011:978-81. doi:10.3850/978-981-08-7724-8.

[4] Brennan S, Molkov, V. Safety assessment of unignited hydrogen discharge from onboard storage in garages with low levels of natural ventilation. Int J Hydrogen Energy 2013. doi:10.1016/j.ijhydene.2012.08.036.

[5] Makarov D, Shentsov V, Kuznetsov M, Mokov, V. Pressure peaking phenomenon: model validation against unignited release and jet fire experiments. International Journal of Hydrogen Energy, Volume 43, Issue 19, 10 May 2018, Pages 9454-9469 
[6] Jallais S, Houssin D, Shentsov E V, Molkov V, Makarov D, Melideo D, et al. Pre-normative research on safe indoor use of fuel cells and hydrogen systems Hyindoor Final Report. 2015.

[7] Xu BP, Wen JX. Numerical study of spontaneous ignition in pressurized hydrogen release through a length of tube with local contraction. Int J Hydrogen Energy 2012;37:17571-9. doi:10.1016/j.ijhydene.2012.04.150.

[8] Molkov V, Shentsov V, Brennan S, Makarov D. Dynamics of Hydrogen Flame Self-Extinction in a Vented Enclosure. Proc Seventh Int Semin Fire Explos Hazards 2013:1-10. doi:10.3850/978-981-08-7724-8.

[9] Molkov V, Shentsov V, Brennan S, Makarov D. Hydrogen non-premixed combustion in enclosure with one vent and sustained release: Numerical experiments. Int J Hydrogen Energy 2014;39:10788-801. doi:10.1016/j.ijhydene.2014.05.007.

[10] Kuznetsov, M., Shentsov, V., Brennan, S. and Molkov, V. Experimental and Analytical Study of Hydrogen Jet Fire in a Vented Enclosure. Eighth Int. Semin. Fire Explos. Hazards, 2016, p. $0-9$.

[11] Xiao, J., Kuznetsov, M. and Travis, J.R., 2018. Experimental and numerical investigations of hydrogen jet fire in a vented compartment. International Journal of Hydrogen Energy, 43(21), pp.10167-10184.

[12] Xiao J, Breitung W, Kuznetsov M, Zhang H, Travis JR, Redlinger R, et al. GASFLOW-MPI: A new 3-D parallel all-speed CFD code for turbulent dispersion and combustion simulations: Part I: Models, verification and validation. Int J Hydrogen Energy 2017;42:8346-68. doi:10.1016/j.ijhydene.2017.01.215.

[13] Hooker, P., Hall, J., Hoyes, J.R., Newton, A. and Willoughby, D., 2017. Hydrogen jet fires in a passively ventilated enclosure. International Journal of Hydrogen Energy, 42(11), pp.75777588.

[14] Molkov V. Fundamentals of Hydrogen Safety Engineering I. eBooks and textbooks from bookboon. com.; 2012.

[15] Molkov, V., Makarov, D. and Bragin, M. Physics and modelling of underexpanded jets and hydrogen dispersion in atmosphere, 2009. Physics of Extreme States of Matter - 2009. Institute of Problems of Chemical Physics, Russian Academy of Sciences, pp. 146-149. ISBN 978-5901675-89-2

[16] Brennan, S., Hussein, H. G., Makarov, D., Shentsov V., Molkov V. Pressure effects of an ignited release from onboard storage in a garage with a single vent. Int J Hydrog Energy 2018 (Submitted).

[17] Shih T-H, Liou WW, Shabbir A, Yang Z, Zhu J. A NEW kt EDDY VISCOSITY MODEL FOR HIGH :REYNOLDS NUMBER TURBULENT FLOWS. Compurers Fluids 1995;24:227-38. doi:10.1016/0045-7930(94)00032-T.

[18] Yakhot V, Orszag SA. Renormalization-group analysis of turbulence. Phys Rev Lett 1986;57:1722-4. doi:10.1103/PhysRevLett.57.1722.

[19] Menter FR. Two-equation eddy-viscosity turbulence models for engineering applications. AIAA J 1994;32:1598-605. doi:10.2514/3.12149.

[20] Menter FR. Improved two-equation k-omega turbulence models for aerodynamic flows. NASA Tech Memo 1992:1-31. doi:10.2514/6.1993-2906.

[21] Launder BE, Reece GJ, Rodi W. Progress in the Development of a Reynolds Stress Turbulence Closure. J Fluid Mech 1975;68:537-66.

[22] Magnussen BF. On the structure of turbulence and a generalized eddy dissipation concept for chemical reaction in turbulent flow. 19th Am Inst Aeronaut Astronaut Aerosp Sci Meet 1981:1-6. doi:doi:10.2514/6.1981-42.

[23] Gran, I. R., Magnussen BF. A Numerical Study of a Bluff-Body Stabilized Diffusion Flame. Part 2. Influence of Combustion Modeling And Finite-Rate Chemistry. Combust Sci Technol 1996;119:191-217. doi:10.1080/00102209608951999.

[24] Magnussen BF. Modelling of NOx and Soot formation by the Eddy Dissipation Concept. Int Flame Res Found First Top Oriented Tech Meet 1989:1-20.

[25] Murthy JY. Finite Volume Method for Radiative Heat Transfer. J Thermophys Heat Transf 1998;12:313.

[26] Yan L, Yue G, He B. Development of an absorption coefficient calculation method potential 
for combustion and gasification simulations. Int J Heat Mass Transf 2015;91:1069-77.

doi:10.1016/j.ijheatmasstransfer.2015.08.047.

[27] Cirrone DMC, Makarov D, Molkov V. Thermal radiation from cryogenic hydrogen jet fires. Int. Conf. Hydrog. Saf., 2017, p. 1-15.

[28] ANSYS Fluent R16.2 User Guide 2016.

[29] Baraldi D, Melideo D, Kotchourko A, Ren K, Yanez J, Jedicke O, et al. Development of a model evaluation protocol for CFD analysis of hydrogen safety issues the SUSANA project. Int J Hydrogen Energy 2016;42:7633-43. doi:10.1016/j.ijhydene.2016.05.212.

[30] Baraldi D, Melideo D, Kotchourko A, Ren K, Yanez J, Jedicke O, et al. The CFD Model Evaluation Protocol. 2016.

[31] Houf WG, Evans GH, Schefer RW. Analysis of jet flames and unignited jets from unintended releases of hydrogen. Int J Hydrogen Energy 2009;34:5961-9. doi:10.1016/j.ijhydene.2009.01.054.

[32] Hubbard GL, Tien CL. Infrared Mean Absorption Coefficients of Luminous Flames and Smoke. J Heat Transfer 1978;100:235. doi:10.1115/1.3450788.

[33] TWC. Weather History for Karlsruhe-Germany May, 20142014. https://www.wunderground.com (accessed March 2, 2018).

[34] Molkov V, Shentsov V, Quintiere J. Passive ventilation of a sustained gaseous release in an enclosure with one vent. Int J Hydrogen Energy 2014;39:8158-68. doi:10.1016/j.ijhydene.2014.03.069.

[35] Baker, W. E., Cox, P. A., Westine, P. S., Kulesz, J. J. A, Strehlow RA. Explosion Hazards and Evaluation. Amsterdam, The Netherlands: Elsevier Scientific Publishing Co.; 1983.

[36] Brennan, S. aand Molkov V., Pressure peaking phenomenon for indoor hydrogen releases, submitted to the International Journal for Hydrogen Energy, 2018

[37] Molkov, V. and Saffers, J.B., 2013. Hydrogen jet flames. International journal of hydrogen energy, 38(19), pp.8141-8158. 